University of Redlands

\title{
Levee Flood Hazard Scenario Analysis Application
}

A Major Individual Project submitted in partial satisfaction of the requirements for the degree of Master of Science in Geographic Information Systems

\author{
by \\ Kevin Charles Long \\ Fang Ren, Ph.D., Chair \\ Mark Kumler, Ph.D. \\ Kristen Heavener
}

December 2008 
Levee Flood Hazard Scenario Analysis Application

Copyright (C) 2008 by

Kevin Charles Long 
The report of Kevin Charles Long is approved.
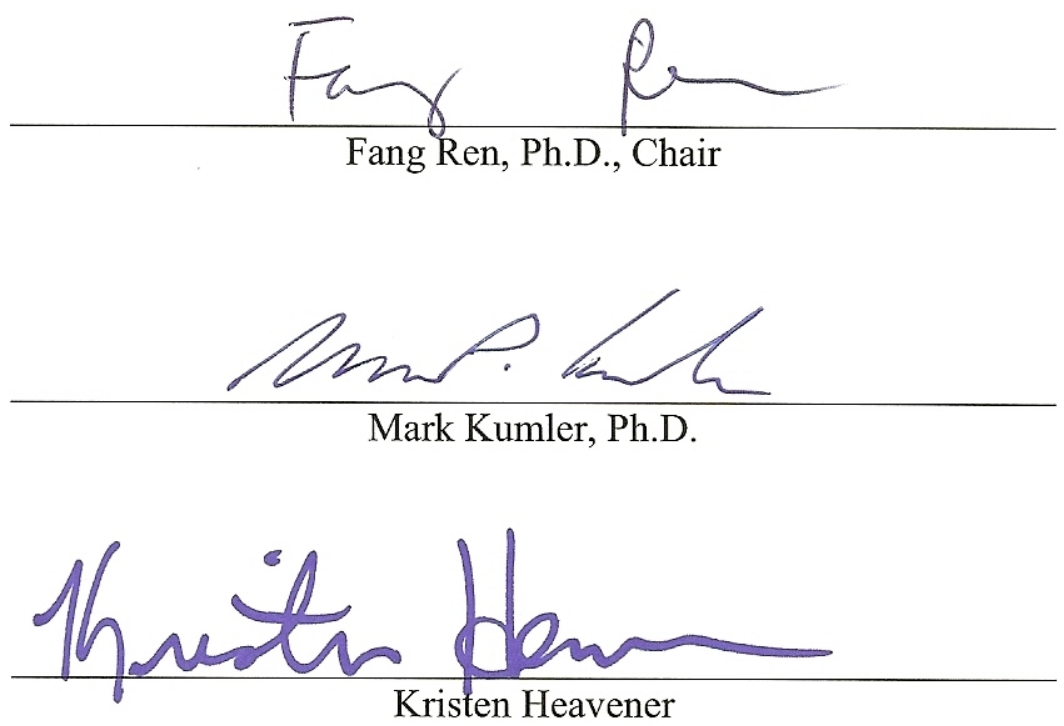

December 2008 



\section{ACKNOWLEDGEMENTS}

A lot of people helped to contribute to my successful completion of this project and the Masters of Science in Geographic Information Systems. First I would like to recognize and thank all the folks at the Federal Emergency Management Agency that supported me and made this possible. My management was responsible for selecting me and allowing me to take advantage of this opportunity and I owe each thanks. They are Paul Huang, Claire Drury, Bill Blanton, Kathy Miller, Fred Sharrocks, Doug Bellomo, and Michael Buckley. Better people I cannot imagine.

My client, Mary Jo Mullen of FEMA, was patient and responsive which made it possible to work on this project while surviving the coursework this year. Kristen Heavener, also of FEMA, was kind enough to travel across the country and sit on my defense committee. I consider both great friends and hope they can continue to put up with me no matter where life may lead us.

I want to thank my friends who have stood by me this year and had the fortitude to endure my good bad days. Allyson Lichtenfels made sure that I stayed on the path to completing this degree and making my way. She talked me off the ledge many times and reminded me of the important things in this life. I am grounded and sure because of her. Bruce Queen kept me from losing my mind and always listened no matter what I might be going on about. He took care of everything while I was away from home and made it possible for me to never have any worries because it was in very good hands. He was selfless as always and gave too much while asking nothing in return.

William Juarez found me just in time and gave me a reason to look up every day. He changed my world and showed me all the wonders Southern California has to offer. Wil taught me there is more to life that I should cherish and celebrate. Everyone that knows him reaps the rewards of his big heart. I am so happy that he had room for me in it.

My family has stood by me the longest and continues to encourage me in everything that I do. This year has been no different. My mother, Linda Long, brother, Steve Long, and sister-in-law, Kimberly Long have held me hand through the worst times and cheered me on through the best times. I can never thank them enough.

I would like to thank the faculty of the University of Redlands who taught me so much in such a short time. My advisor deserves many thanks for her guidance throughout this process and for the patience that she had even when I hadn't made the progress she had hoped. Fang Ren helped me to think through things and always provided a gentle and sometimes not so gentle nudge to keep me going in the right direction. 



\begin{abstract}
Levee Flood Hazard Scenario Analysis Application

by

Kevin Charles Long
\end{abstract}

The development of a GIS Application based on ArcGIS version 9.2 was determined to fulfill the requirements of the Federal Emergency Management Agency for calculating the impacts of different flood hazard scenarios using the flood hazard data available to them with other publicly available data such as census data. The application was designed and implemented to be used by non-geographic information system professionals to use the tools and perform the necessary analyses required to formulate the needed results. The implemented application is made up of a file geodatabase to store the data, a toolset to help define the flood hazard polygons for a specific flood scenario, and models to perform routine analyses of the scenarios to determine some of the impacts on a community. Impacts such as population impacted, housing units impacted, and miles of levee in an area were implemented using models in ArcMap. This application will show the potential power of the geospatial flood hazard data that FEMA is producing as part of their Map Modernization efforts and showcase its use in a geographic information system. 



\section{Table of Contents}

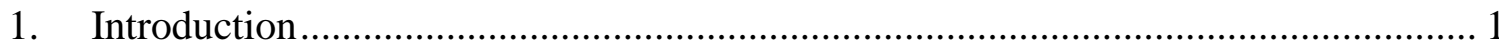

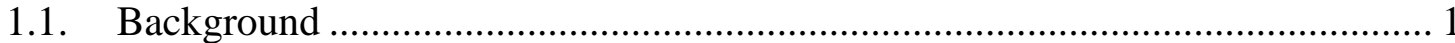

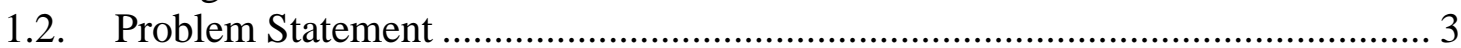

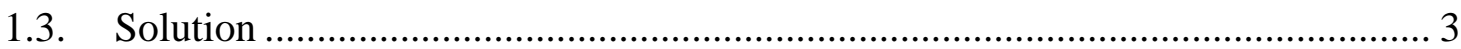

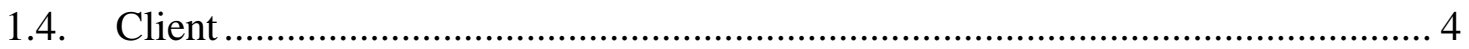

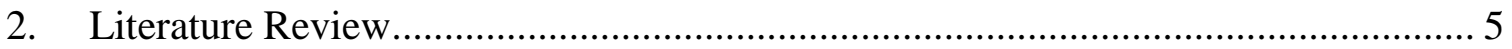

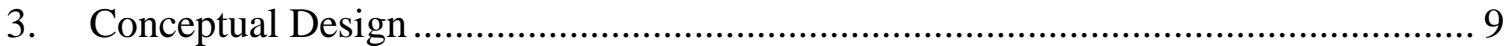

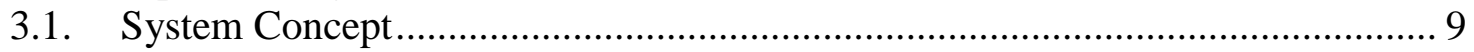

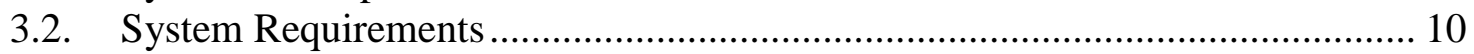

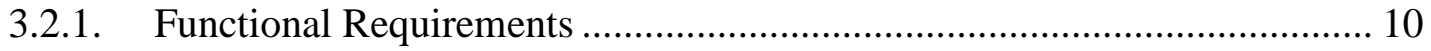

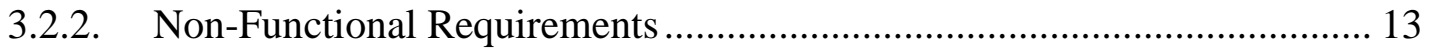

3.3. System Architecture Concept ....................................................................... 13

3.4. Software Concept .................................................................................. 14

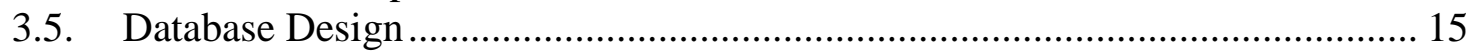

3.6. User Interface Conceptual Design............................................................ 18

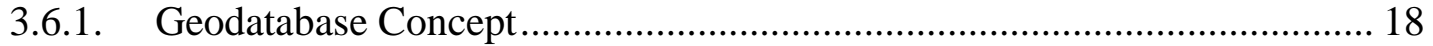

3.6.2. Toolset Concept ................................................................................ 18

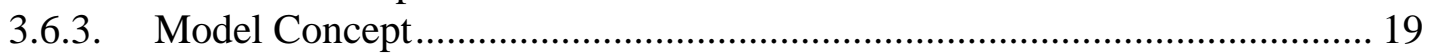

3.6.4. Map Production Concept .................................................................... 20

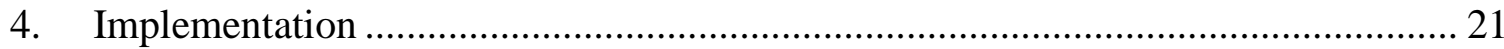

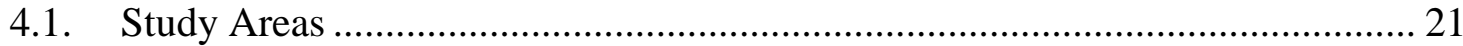

4.2. Implementation Overview ...................................................................... 23

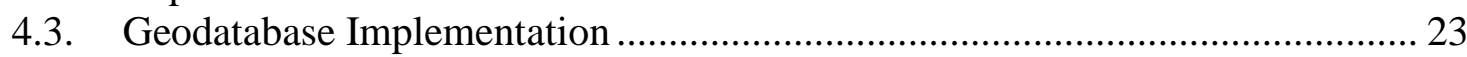

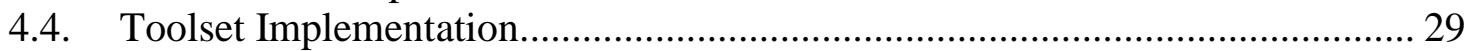

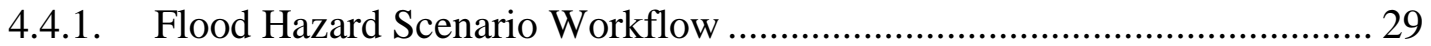

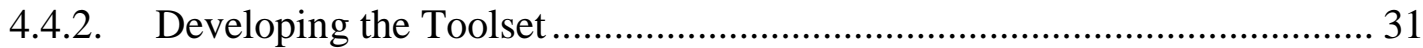

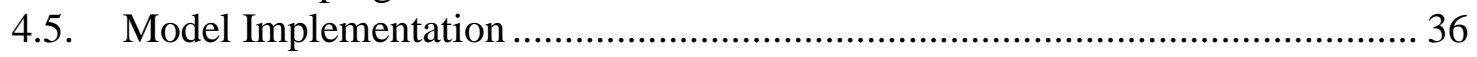

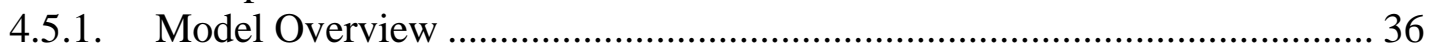

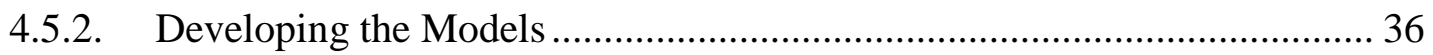

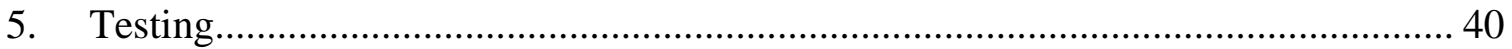

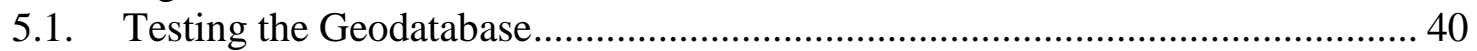

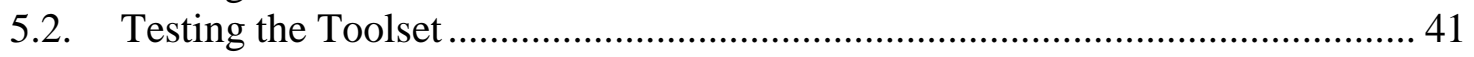

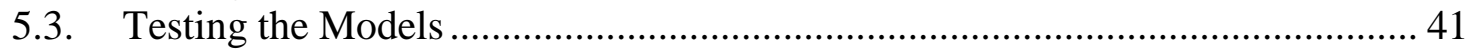

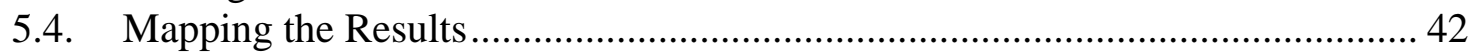

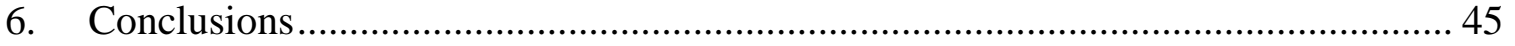

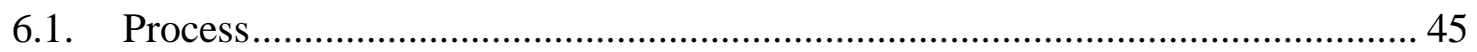

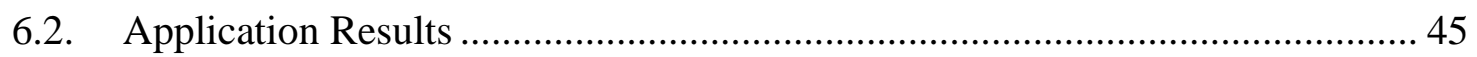

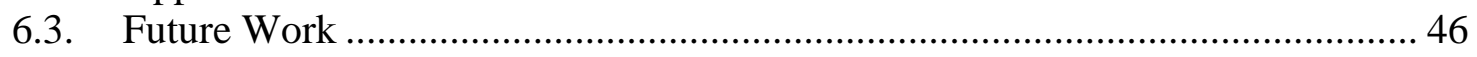

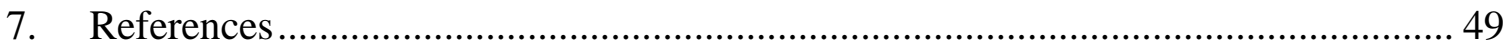




\section{Table of Figures}

Figure 3.1 Conceptual System Architecture Diagram .............................................. 14

Figure 3.2 Geodatabase Conceptual Design Schematic ........................................... 15

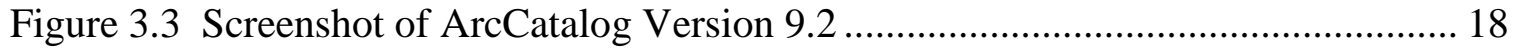

Figure 3.4 Screenshot of ArcMap Version 9.2 showing ArcToolbox ............................ 19

Figure 3.5 Example of a Model Created Using ModelBuilder ..................................... 20

Figure 4.1 Study Areas for Application Implementation......................................... 22

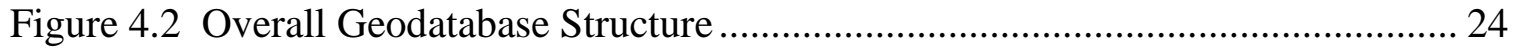

Figure 4.3 Flood_Control_Levees Feature Dataset Diagram ..................................... 25

Figure 4.4 Sample Flood Hazard Feature Dataset ....................................................... 26

Figure 4.5 Implemented Application Geodatabase and Folder Structure ....................... 29

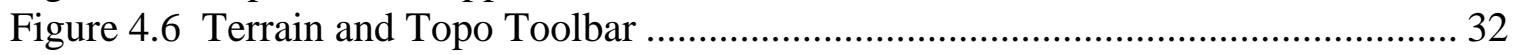

Figure 4.7 Create New Scenario Feature Class Model in the ArcToolbox .................... 33

Figure 4.8 Flood Hazard Scenario Creator Toolbar................................................... 33

Figure 4.9 Implemented Flood Hazard Analysis MXD in ArcMap Showing Toolbars .. 35

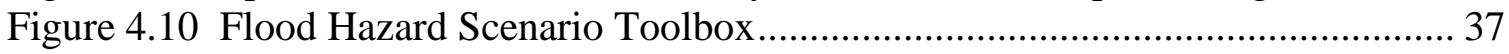

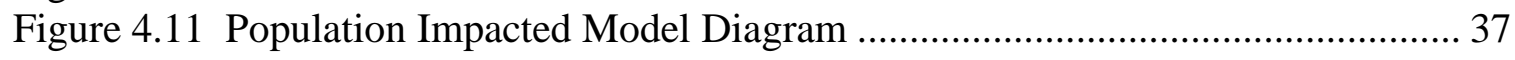

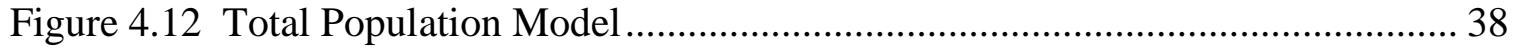

Figure 4.13 Results of Housing Units Impacted Model ............................................ 39

Figure 4.14 Total Length of Levee in Area Model Diagram ........................................ 40

Figure 5.1 Results of the Population Impacted Model in an Area of San Bernardino .... 43

Figure 5.2 Results of the Housing Units Impacted Model for an Area in Sacramento ... 44

\section{List of Tables}

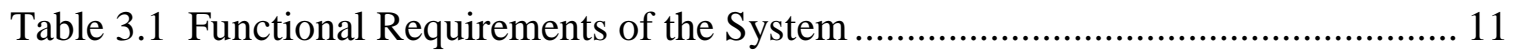

Table 3.2 Description of Feature Classes, Tables, and Folders …................................ 17

Table 4.1 Flood Hazard Feature Data Breakdown and Feature Class Descriptions ........ 27

Table 4.2 Flood_Hazard_Scenario_Template Main Attributes ................................... 28

Table 4.3 Create Flood Hazard Scenario Use Case ..................................................... 31 


\section{List of Acronyms}

$\begin{array}{ll}\text { FEMA } & \text { Federal Emergency Management Agency } \\ \text { DEM } & \text { Digital Elevation Model } \\ \text { GIS } & \text { Geographic Information System } \\ \text { MIP } & \text { Mapping Information Platform } \\ \text { MS GIS } & \text { Master of Science in Geographic Information Systems } \\ \text { MXD } & \text { ArcMap Map Document } \\ \text { VBA } & \text { Visual Basic for Applications }\end{array}$





\section{Introduction}

The Federal Emergency Management Agency (FEMA) is responsible for classifying levees as having met certain requirements for providing protection from the 1 percent annual chance flood. This classification determines flood insurance rates which are based on the resulting flood hazard depiction. The type of flood hazard also determines whether flood insurance is mandatory for a property with a federally-backed mortgage. Using both geospatial data and the tabular data that FEMA collects, this project provides FEMA with a solution to analyze, report, and communicate the impact of different flood hazard scenarios on the areas affected by levee classification.

Specifically, a GIS application is developed in this project which allows the user to create various flood hazard scenarios based on the levee or levee system classification in the area(s) of interest, and to obtain the corresponding impacts caused by the created scenarios, such as the spatial distribution of impacted household and the number of households. This will help decision makers at all levels of government to be better informed and communicate levee-related flood risks, and different levels of flood risk in general, to individual property owners and the public.

\subsection{Background}

The Federal Emergency Management Agency (FEMA) is responsible for identifying the flood hazards for the nation through the National Flood Insurance Program (NFIP). This program makes flood insurance available to individuals who have property in a community that participates in the program. Participation requires that the community adopt a minimum level of floodplain management ordinances. In return, the federal government makes flood insurance available to property owners in that area.

The NFIP produces a set of national maps, referred to as the Flood Insurance Rate Maps (FIRMs), to determine whether a property is located in a Special Flood Hazard Area (any area which would be inundated by the 1 percent annual chance flood) for flood insurance rating purposes, as well as to determine if the purchase of flood insurance is mandatory. The Flood Insurance Rate Maps inform community officials, property owners, planners, and floodplain managers about the level of flood risk.

The identification and representation of flood hazards in areas where levees are present are dependent on the classification of the levee. The flood hazard depiction for the FIRMs is based on whether or not the levee provides protection from the 1 percent annual chance flood. If the levee can be shown to provide protection, the area behind the levee will be identified as a moderate risk area. Correspondingly, flood insurance is generally cheaper and not mandatory. If the levee cannot be shown to provide protection, then the area is shown as a Special Flood Hazard Area and the flood insurance premiums are higher. The impact of levee classification changes on the community and property owners due to changes on the map can be perceived as significant. One of the factors is the resulting flood insurance requirement when a levee can no longer meet the criteria necessary to be classified as providing protection. As a result, remapping of leveeimpacted areas must be done very carefully and publicly. 
Starting in 2004, FEMA undertook a nationwide effort to modernize the flood hazard mapping inventory through a program called Flood Map Modernization. As part of this effort, FEMA has examined levee documentation for those levees shown on the maps as providing protection from the 1 percent annual chance flood to determine if they continue to meet the criteria necessary for this classification. The examination has resulted in many levees being reclassified or given a temporary classification and the areas behind them remapped. The temporary classifications of providing protection have set expirations which must be tracked so the levees can be reassessed to determine if the documentation is complete and meets all the criteria necessary to maintain the protection classification.

This tracking process is complicated. The mapping process captures information used to determine and delineate flood hazards in the Digital Flood Insurance Rate Map (DFIRM) database. The DFIRM is the final dataset for a county or community mapped by FEMA representing the flood hazard data, along with other attributes such as cross-sections, political jurisdictions, and annotation. The levee locations and other information are stored in a separate geodatabase referred to as the Midterm Levee Inventory. The Midterm Levee Inventory captures levee centerlines, floodwall centerlines, and closures for levees identified by FEMA and the U. S. Army Corps of Engineers. The tracking for the flood hazard mapping projects is done through a workflow tracking system in FEMA's Mapping Information Platform (MIP). The MIP tracks project status in terms of project percent complete, as well as administrative progress for flood hazard mapping projects. The MIP does not capture data regarding levees, but does track the mapping project determining the flood hazards in levee impacted areas from start to completion. This tracking includes the production of the data used to create the DFIRM, as well as all the administrative work entailed in making the map official and having it adopted by the communities. The tracking data have many relationships that the individual systems were not designed to support.

The fragmentation of the data into separate databases and systems makes even the simplest analysis extremely challenging. Using spatial context in the data sets, together with tools to establish the correspondence among the data in the databases, will help improve FEMA's ability to analyze how levees are classified, the flood hazards associated with those classifications, and the impact they have on a community. This information will assist outreach efforts when a levee's classification is changed.

Performance of these analyses and communication of the results is crucial to FEMA's mission to mitigate the loss of life and property caused by flooding and levee failures. Knowing where the levees are located and the potential flood hazards associated with them, along with other information like population and housing units, make this analysis possible. The result is a powerful tool for decision making at multiple levels of government for external stakeholders, and for the individual property owner. 


\subsection{Problem Statement}

Data about the levees, including geospatial data, shown on the Flood Insurance Rate Maps have been collected and stored in a database called the Midterm Levee Inventory. The extents of the 1 percent annual chance flood are captured in the individual Digital Flood Insurance Rate Map (DFIRM) databases, along with other information, such as cross-sections used in the flood models. The tracking and status of the flood hazard mapping projects are done through a workflow system stored in FEMA's Mapping Information Platform (MIP). However, levee information is not captured in this system. The MIP captures data related to the individual elements, such as terrain data acquisition and hydraulic modeling development, needed to create the DFIRM databases, and overall progress toward final database and map products. The MIP also tracks all administrative processes involved in making the final database and map, such as statutory appeal periods and notifications for the FEMA's map production process.

Fragmentation of data across multiple systems makes it extremely difficult to analyze or report on progress and status with respect to levee mapping. For example, the geospatial data on levees, such as geographic location, physical alignment, and jurisdiction location are not linked to the other databases, which make it impossible to conduct spatial analysis on the impact of changing flood hazard areas based on FEMA's current systems.

In such situations, the problem faced by FEMA is rather complex because the audience varies widely, along with the questions being asked of FEMA's flood hazard mapping staff. However, one problem commonly faced by FEMA's mapping staff is how to perform analyses to determine the potential impacts caused by the changing flood areas, which is due to fragmented data and lack of available tools. Therefore, the flexibility to examine different flood hazard scenarios without developing new flood models would be very valuable for them to estimate the impacts on an area and the people living in those areas. This would allow FEMA staff to produce analysis results they can communicate to decision makers and stakeholders, as well as the public.

\subsection{Solution}

Based on the problem described in the last section, FEMA required an easy to use system which enables its staff to quickly represent and analyze flood hazard scenarios in relation to different levee classifications. In light of the spatial analyses involved in the requested system, it was decided to adopt a GIS solution to address the client's needs due to the power of GIS in spatial data management and analysis. Therefore, a customized GIS application was developed to facilitate FEMA staff analyzing different flood inundation scenarios based on specific levee classifications, so that the results could be presented to both technical and non-technical audiences.

More specifically, the GIS application was implemented with ArcGIS 9.2 and it contains three major components: a geodatabase, a set of tools and toolbar, and models. First, the application allows the user to input data from either existing flood hazard data or userdefined flood hazard inundation areas and the data can be easily stored and updated in the geodatabase developed in the project. Second, in order to guide the user through steps to create a feature class for a specific flood hazard scenario, a toolbar was also developed in 
ArcMap. Last, the application contains several models that can automate the analyses. For example, one critical spatial analysis for this project is to determine the impacts on the community of the levee classification flood inundation scenarios by using the input data from users and census data for population and building units.

In general, the solution will enable the client to provide both internal and external stakeholders with flood hazard scenario analysis results to assist them in their decision making and make them better informed about the impacts of the different flood hazard scenarios. This will eventually assist FEMA in their efforts to mitigate the loss of life and property with respect to flooding. Further, the GIS solution in this project will make FEMA staff use GIS to analyze flood hazard data that is being created through Flood Map Modernization, which is highly desired by the client.

\subsection{Client}

The client for the Levee Flood Hazard Scenario Analysis Project was Mary Jo Mullen, P.E., of FEMA's Mitigation Directorate, Risk Analysis Division, Engineering Management Branch. Mullen's responsibilities include the oversight and coordination of levee issues related to FEMA's Flood Map Modernization Program, and flood hazard mapping in general. Mullen is an expert in both flood hazard mapping and in FEMA's technical and regulatory requirements for levee classification.

The client provided the technical expertise regarding FEMA's technical and regulatory requirements with respect to flood hazard mapping and levee classifications. The client also specified the type of data needed in order to analyze the impact of flood hazard changes due to levee classifications, as well as the progress and status of levee mapping in the Flood Map Modernization Program. The client provided insight into the type of analyses and data management issues required after map modernization so that this solution will continue to be viable and expandable for FEMA's purposes for the foreseeable future.

Mullen's knowledge of FEMA, the National Flood Insurance Program, flood hazard analysis and engineering, flood hazard mapping, and levee classifications was a critical resource for the design, development, and implementation of this solution. 


\section{Literature Review}

Topics with a focus on Geographic Information Systems (GIS) ranging from risk communication to levees have been reviewed to determine what previous work has been done or can be related to solving the problems relating to flood hazard mapping and levees. The topic of most articles relating flood hazards to GIS is how to provide better interfaces for hydrologic and hydraulic modeling, especially flood prediction models. FEMA already utilizes many of these solutions in creating flood hazard maps. An interdisciplinary review is necessary to fully understand the problems FEMA faces for analysis, decision-making, and risk communication to determine if there is a solution that can be provided using GIS.

A paper by Sebhat and Heinzer (1997) regarding development of an ArcInfo Interface to the National Weather Service DAMBRK Model provided insight into how GIS has been used in similar flood analyses. The DAMBRK Model is used to simulate the failure of dams, which for the purposes of this review is very similar in nature to the failure of levees during a flood event. Sebhat and Heinzer performed work the U.S. Bureau of Reclamation, which they describe as having similar responsibilities to FEMA in developing flood inundation maps. Sebhat and Heinzer created an ArcInfo Interface to input data in the model and to utilize output from the model, which is a large undertaking and requires substantial data resources. For display purposes, the authors used output from the DAMBRK model in ArcInfo as an input into their GIS Software package. Using ArcInfo to create a Triangulated Irregular Network (TIN) of the water surface elevations calculated by the DAMBRK model, they overlaid that TIN over a Digital Elevation Model (DEM) hillshade for visualization purposes. Even this simple representation of the flood hazard on a surface communicates information that most nonengineers and non-geospatial professionals could not get from tabular output data from a model. One problem is the large amount of data required for this to be applied anywhere in the country (Sebhat \& Heinzer, 1997).

Another crucial facet of the levee problem is flood risk communication. Witherell and Hahn (2000) provided some insight into an approach for communication solutions by laying out the problems they faced with large-scale environmental cleanup. The risk communication challenges are similar to those which FEMA faces in terms of a wide stakeholder base and the involvement of multiple levels of government. The authors state:

"Almost any large-scale environmental cleanup, especially one where contamination has crossed geo-political boundaries, will result in a project with many stakeholders. Some of the stakeholders involved in this project included: local residents, and community leaders, local government officials, state regulators, federal regulators, and the responsible party. These stakeholders come from a variety of educational and occupational backgrounds, and present a challenge to environmental professionals whose job is to explain the nature and extent of contamination and contamination migration" (Witherell \& Hahn, 2000). 
This explanation of the stakeholders and the issue are directly applicable to FEMA's challenge of flood risk communication especially in areas impacted by levees.

The data problems that Witherell and Hahn describe are also common to FEMA's data. The datasets vary in nature from geospatial datasets to tabular datasets. The authors state that that all the data used in analyses like these have a spatial component (Witherell \& Hahn, 2000) Witherell and Hahn's conclusion was that their case study "illustrates the efficiency and rapid decision-making that can be achieved through the use of GIS tools that dynamically link environmental data to spatial mapping and analysis tools" (Witherell \& Hahn, 2000). This type of data linking for analysis was very successful in terms of providing decision makers with faster, easy to understand results.

Using GIS to perform analyses on spatial data to determine risk was researched by Mennis to determine if particular racial groups are more at risk of environmental hazards to do the location of hazardous materials in proximity to where these groups live. The research highlights the issues with performing such spatial analyses and ways to mitigate those issues. In this particular case, census data and the scale of analysis were the main issues. The scale issue brings up the problem with the Modifiable Areal Unit Problem (MAUP) when doing analyses with data at different scales and different scale aggregations. The census data brings presents the issue of having these spatial units representing the community within that unit in generalities that are aggregated together. Mennis's proposed to create a multiscale methodology to account for the issues caused by the MAUP and provide more granularity in the data describing people's characteristics. The proposal called for a surface to be developed rather than using polygons or points to aggregate the characteristics of an area. The conclusion was that this would be successful with more data developed using a raster surface rather than vector data as conventionally done (Mennis, 2002).

Jelinski and Wu (1996) identify several approaches for dealing with MAUP. The suggested procedure is "first to identify the characteristic scales using methods such as spatial autocorrelation, semivariograms, fractal analysis, and spectral analysis, and then to focus the study on these scales." The MAUP was an important factor for this project because of the uncertainty that is introduced into the results. This has severe implications for the decision support aspects (Jelinski \& Wu, 1996).

The MAUP is one consideration that GIS users must always be aware of in their analyses to better understand their results. The data also presents the problem caused by aggregation of values in an area or spatial unit. Steel and Holt researched the issue of ecological fallacy to determine the impacts of group level data analysis on results that are then interpreted as applying to individual levels. The relationships between the attribute values of the groups were determined to better understand what variation existed within the data such that a better understand of how the variations might affect individual values taken from group analyses. They developed models to better group data so that the values would more closely represent the values of the individuals being grouped. They also suggested mathematical approaches for accounting for the aggregation effects within 
the data. The determined that if the grouping variables used to define the units were identified and the relationships between the groups were known, that they could be accounted for in the analyses to better estimate individual values. (Steel \& Holt, 2008)

Zerger's paper discusses the importance of knowing the uncertainty of data and the chance of error being introduced through analysis. This discussion points out that decision makers often take maps or graphics as accurate representations and may accept them without questioning the data used to create them. The level to which the uncertainty in the data is communicated to the end user or decision maker is dependent upon the situation. In Zerger's scenario, dealing with evacuation prior to a flood event, it was determined that sharing the uncertainty with the public may affect their decisions to participate in the evacuation if they did not feel the data were accurate. For decision makers, Zerger determined that presenting more versions of the results was effective in helping the decision makers understand the uncertainty and factor it in to the decision making process. The uncertainty of the data and its importance to the decision making process is also a function of scale. At regional levels, uncertainty of local data may not be important but it still must be considered to ensure the validity of the results. It is very similar to the issue of the MAUP and must be considered in much the same way with regard to this project (Zerger, 2002).

A review of previous works on decision support systems with a focus on natural risk and flood risk related systems determined that the most critical elements of the system are the outputs or products of the system (Levy, 2005). The outputs must be clear and concise and present only the data critical to the decision. Too much information either digitally or on hardcopy maps slows the user's ability to comprehend the data. Decision makers need to be able to understand the data that is being presented and quickly formulate decisions. The concept of multiple criteria decision making coupled with a decision support system is presented well in Levy's paper, in which these systems were used for flood risk management. One of the key components of the system, a graphical user interface, enables the user to both perform analyses and present results (Levy, 2005). The interface was found to be the most critical feature in creating a GIS decision support system because it is how the user provides input into the analysis to be performed, as well as interpreting the results produced by the system.

Vickers discusses the complications involved with designing a decision support system that will be used by users of varying skill levels. The complexity of the system is driven by the end user. The more familiar the end user is with the system or similar systems the more value that user will achieve through using the system. Vickers suggests that creating a system that is scalable so that new users can use the system at a different level from expert users is beneficial. Users are expected to train to become expert users to make full use of a complex system, but there are issues of time, cost, and motivation for this to be successful. Involving the users in the design of the system helps make the users part of the process and more motivated to use and learn the system. If the end users find the system useful and easy to use, then they are more likely to adopt it and to continue using it. Designing the system for end users of a certain skill level is suggested as the most appropriate method for achieving success. Providing training to get the end users to 
that skill levels is the main requirement, but negates creating an overly complex system with different layers of functionality. (Vickers, 1994)

Developing a decision support system also requires a process be used to design and build the decision support system. Jankowski, Robischon, Tuthill, Nyerges, and Ramsey detail the steps that they followed to develop a decision support system from the inception of understand the problem to testing the end product to determine if it met the end users' needs. The solution involved using ArcGIS along with Microsoft office products to build a user interface that allowed the end users to access all the data and tools from one interface. They found that having the end users work between different applications moving various data around was too cumbersome and distracted the end users from the analysis and decision making process. They detail the importance of obtaining well defined requirements as well as understanding the value the end users place on the requirements and the various factors being analyzed by the final application. They also noted that the background of the end users was important to take into account in the design of the application. The team was faced with constraints for the application involved with the software such that they could meet the end users needs with their available resources. They found that ArcGIS provided them with tools (ArcObjects) that made customization of the application possible and could be used after deployment to further enhance the application. They found that the system they developed was most successful because the design took into account the requirements and constraints of the end users. They found that the application could have been improved if the end users had been more available throughout the designing and building of the application. Reviewing the system at every stage of the development with the end users would have been beneficial to the overall end product. (Jankowski, Robischon, Tuthill, Nyerges, \& Ramsey, 2006)

Ahmad and Simonovic worked to develop a model that would estimate the flood hazards for different scenarios based on factors such as the height of levees, rainfall amounts, river depth and other factors. The application they developed was built on System Dynamics and ArcView. The two were linked together using scripts that transferred data between the two programs. This allowed the GIS to manage and provide data to the System Dynamics to perform calculates to determine flow and the impacts of changing variables over time for flood modeling. There were problem experienced with transferring data back and forth between the two programs. They were not able to fully automate the updating the results between the two systems. The difference in the data structure between the two systems also caused problems with the final application. The approach detailed by Ahmad and Simonovic required a substantial investment in time and effort. This application was also data intensive and required high accuracy topographic raster data for the areas being modeled. The system used the raster cells to perform calculations of flow for rivers and for overland flow areas, which was successful in approximating the behavior of flood waters. (Ahmad \& Simonovic, 2004) 


\section{Conceptual Design}

\subsection{System Concept}

This system was designed to provide the FEMA Engineering Management Branch staff with a set of tools to perform analytical functions that are presently not readily available to them. The analytical functions were designed based on existing data sources that FEMA has access to, along with data that will be user-generated through this system. A general overview of how the system provides this functionality can be described in 5 stages. The stages are data setup, database maintenance, data creation, perform analyses, and generate output.

During the data setup stage the user first launches the system and provides the required data sets to appropriately populate the database. Because the data required for the analyses comes from several different sources and systems, the appropriate components from each source must be compiled into one database to allow the user to easily navigate to the data and to allow the system to locate the data for automated analyses. Once the data has been compiled into a single database, maintenance of the data becomes an issue as the data from the various data sources is updated.

The data maintenance required for the system is based on the update of the data in the source systems. When the other sources are updated, the data in this system will need to be input into the database, again so that there are no discrepancies between the source data and the data in this system being used in the analyses. The user will provide the latest version of the source data set and use a tool to overwrite the original data in the database. This ensures that the data in this system is up-to-date and duplicate copies of this data are not present. Once the database is populated or updated, the user will be able to use this data to prepare for the analyses they would like to perform for an area.

In the data creation stage the user must decide if the data in the system can be used to represent the appropriate flood hazard scenario or if new data should be created to represent the appropriate scenario. The system will provide tools to assist the user in developing the flood hazard scenario necessary for analyses. Multiple scenarios may be necessary to provide the results needed. The two basic scenarios necessary are for levees that provide protection from the 1-percent-annual-chance flood and those levees that do not provide protection from the 1-percent-annual-chance flood. Once the flood hazard data for these scenarios has been generated, the user can perform the necessary analyses.

In the perform analyses stage, users can use the data in the database and the user-created data to do spatial analyses or queries that answer questions about the flooding scenarios. The Functional Requirements section explains the type of information being generated from these analyses and addresses questions such as what is the population impacted by the flood hazard scenario? What FEMA mapping projects are impacted by the levees in question? 
The system will also allow the user to view or print analyses results in tabular and map formats. This is the output stage. Based on the analyses that the user performed, the system will provide reports and maps to communicate the results of the analyses. The tabular data will be used to insert the numerical results into other materials or reports. The map outputs will also be used for reporting and briefing purposes and may be standalone or included as part of other documentation depending on the intended audience.

These five stages represent the general overview of how the system will operate. The system will fulfill the functional and nonfunctional requirements stated in this document to provide the end user with the analytical capabilities required.

\subsection{System Requirements}

\subsubsection{Functional Requirements}

The functional requirements for this project were broken into groups based on overall system requirements, database and data access, and the user interface components. These requirements were developed through communications and an interview with the client, Mary Jo Mullen of FEMA, to determine the specific needs of the system. The data to fulfill these requirements were documented in Table 3.1. 
Table 3.1 Functional Requirements of the System

\begin{tabular}{|c|c|}
\hline 1 & Overall System Requirements \\
\hline 1.1 & $\begin{array}{l}\text { System will use the following data: } \\
\text { 1. Midterm Levee Inventory (MLI) database } \\
\text { 2. Management Information Platform (MIP) Study Data Excel Reports } \\
\text { 3. Census Block Group Data } \\
\text { 4. County Spatial Data } \\
\text { 5. State Level Spatial Data } \\
\text { 6. Provisionally Accredited Levee (PAL) Tracking Spreadsheet } \\
\text { 7. DFIRM Databases } \\
\text { 8. Topo Data }\end{array}$ \\
\hline 1.2 & $\begin{array}{l}\text { Be able to print using wide variety of printers and paper sizes. ( } 81 / 2 \times 11 \text { to Poster } \\
\text { Size) }\end{array}$ \\
\hline 2 & Database/ Data Access - Data Setup and Maintenance \\
\hline 2.1 & Build a database from the various data sources listed in Requirement 1.1. \\
\hline 2.2 & $\begin{array}{l}\text { Allow the user to update portions of the database when updates are made to the data } \\
\text { sources. Updates will be made to the Midterm Levee Inventory, Management } \\
\text { Information Platform Study Data, Provisionally Accredited Levee Tracking } \\
\text { Spreadsheet, and DFIRM Database data in the system. }\end{array}$ \\
\hline 2.3 & $\begin{array}{l}\text { Allow the user to add topo data, if available, to the analysis to help define the flood } \\
\text { hazard areas. }\end{array}$ \\
\hline 2.4 & $\begin{array}{l}\text { Allow the user to add imagery data, if available, to the analysis to help define the } \\
\text { flood hazard areas and provide base map data. }\end{array}$ \\
\hline 3 & User Interface - Data Creation \\
\hline 3.1 & $\begin{array}{l}\text { Allow the user to create a polygon(s) to represent the areas being inundated for } \\
\text { analysis. }\end{array}$ \\
\hline 3.2 & Allow the user to identify the levees that make up the system. \\
\hline 3.3 & Show the levee system centerlines from the Midterm Levee Inventory data. \\
\hline
\end{tabular}




\begin{tabular}{|c|c|}
\hline 4 & User Interface - Perform Analyses \\
\hline 4.1 & Local Analyses \\
\hline 4.1 .1 & $\begin{array}{l}\text { Allow the user to select the floodplain areas and change them from one Zone Type to } \\
\text { another. }\end{array}$ \\
\hline 4.1 .2 & Calculate the number of housing units impacted by the flood hazard scenarios. \\
\hline 4.1 .3 & Determine which communities are impacted by the levee system. \\
\hline 4.1 .4 & Determine the population impacted by the flood hazard scenarios. \\
\hline 4.1 .5 & $\begin{array}{l}\text { Determine which FEMA mapping projects are impacted by a levee system and } \\
\text { determine the status of those mapping projects. }\end{array}$ \\
\hline 4.2 & National Analyses - Optional \\
\hline 4.2 .1 & Determine the number of Provisionally Accredited Levees (PALs) rejected. \\
\hline 4.2 .2 & Determine the number of PALs signed. \\
\hline 4.2 .3 & Determine the number of PALs offered. \\
\hline 4.2 .4 & Determine the number of effective FEMA mapping projects with levees. \\
\hline 4.2 .5 & $\begin{array}{l}\text { Determine the number of ongoing FEMA mapping projects with levees. (Physical } \\
\text { Map Revisions as well as Countywide Projects) }\end{array}$ \\
\hline 4.2 .6 & $\begin{array}{l}\text { Determine when the PAL(s) is expiring. Report globally how many are expiring in a } \\
\text { specific timeframe. }\end{array}$ \\
\hline 4.2 .7 & Determine when the PAL(s) one-year review is occurring for each levee system. \\
\hline 5 & User Interface - Generate tabular reports from analyses \\
\hline 5.1 & Allow the user to generate reports showing the output results of their analyses. \\
\hline 5.2 & $\begin{array}{l}\text { These results should be easily copied into other applications such as Microsoft Excel } \\
\text { and Word for manipulation and report preparation. }\end{array}$ \\
\hline 6 & User Interface - Generate Maps \\
\hline 6.1 & 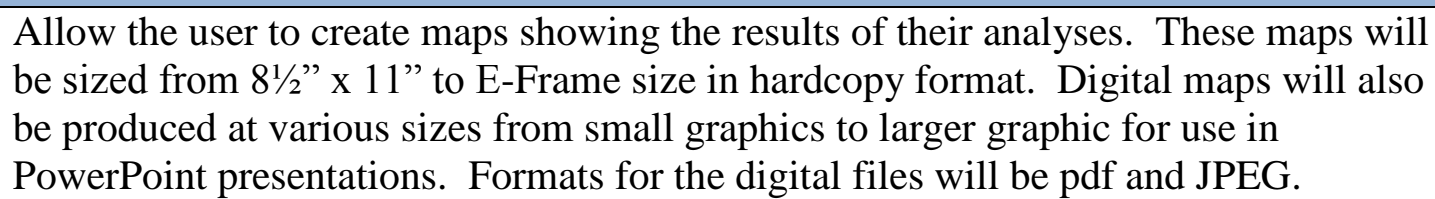 \\
\hline
\end{tabular}




\subsubsection{Non-Functional Requirements}

The nonfunctional requirements for this project were the overall expectations of the system by the client and end users. This list was compiled from comments and knowledge of the client and their working environment.

- The system will help the Engineering Management Branch staff learn to use ArcGIS along with the DFIRM data that FEMA has produced to perform analyses and begin to use the digital DFIRM data over the paper maps.

- The system shall be easy for the Engineering Management Branch staff to learn and use, based on their computer skills and frequent use of computer software.

- The system shall use software that the Engineering Management Branch have on their computers or can be installed by their IT staff.

- The system shall work logically in a step-by-step manner so that the staff understands what is being done. The results will be easily comprehended.

- The system can be loaded onto existing computers as needed. Individual installations will be necessary.

- The system will not interface with any of their other databases or systems. The data will be exported from the other systems for use with this application.

\subsection{System Architecture Concept}

The system architecture for this project was built on the ArcGIS Version 9.2 software platform. The overall system architecture is shown in Figure 3-1. The various data inputs were to be incorporated through a geodatabase using ArcCatalog. Imagery and topographic data sets may also be utilized for analysis, but were not incorporated into the geodatabase. The geodatabase, imagery data, and topographic data were chosen to be stored either locally or on a network drive for access by the software. The geodatabase allows for the update of the data from the Midterm Levee Inventory database, DFIRM databases, and tabular report data. ArcGIS was used to create new data for various Levee Flood Hazard Scenarios. ArcGIS was specified as the software to be used to perform the analyses necessary to produce the results. Models were created to perform the routine analyses defined by the System Requirements. ArcGIS was also specified to be used to produce the tabular reports as well as the digital and hard copy map products. The overall system architecture is show in Figure 3.1. 


\section{System Architecture}

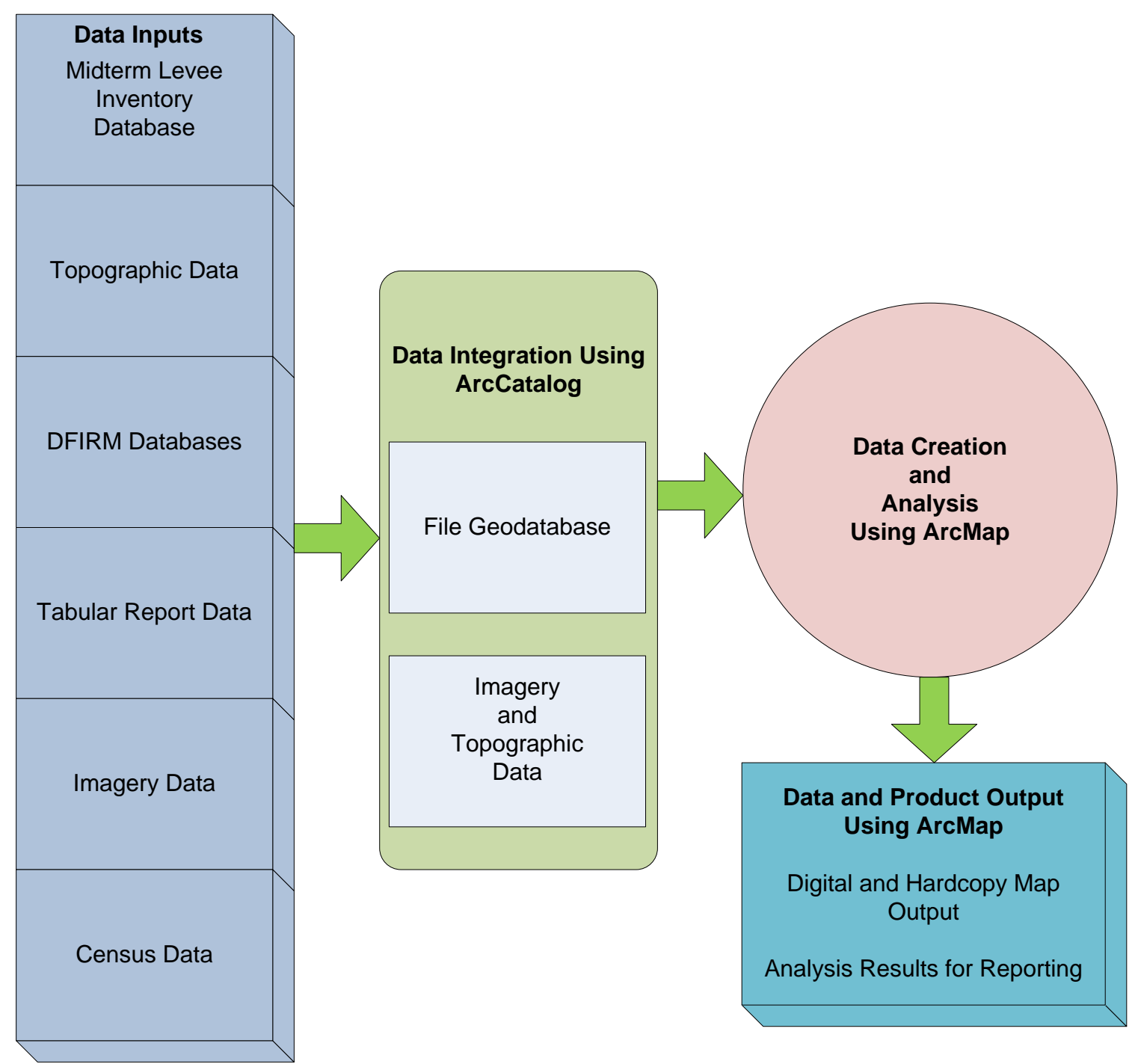

Figure 3.1 Conceptual System Architecture Diagram

\subsection{Software Concept}

The software concept was based on the ArcGIS 9.2 software at the ArcInfo license level. The data inputs for the system were shapefiles, excel tables, raster datasets, and feature classes. The Midterm Levee Inventory database, DFIRM databases, and tabular excel data were to be loaded into the database using Python Scripts to automate the process. The topographic data, imagery data, and census data were loaded manually through ArcCatalog as necessary by the user. The data editing was determined to be done using ArcMap with some customization using ArcObjects thus creating a toolset for the users to edit and creating new flood hazard feature classes to be used for the scenario analyses. ArcMap was used to perform the analyses. It was determined that models would be created using ArcGIS ModelBuilder to automate the routine analyses required for the 
system. The models and the toolset were stored in a MXD file. ArcMap also provided the functionality to produce the final tabular output and produce the digital and hardcopy map products required to exhibit the results of the analyses. End users will work using their desktop computers. The geodatabase and other data may either be stored locally on the user's computer or on a local network so that more than one user may access the data. The only interface with the user was designed to be through their personal computer workstations. There are no interoperability or interface requirements with other systems.

\subsection{Database Design}

The Database Design was based on a File Geodatabase with the imagery data and topographic data stored outside of the geodatabase. Figure 3.2 shows the conceptual schematic of the geodatabase. The DFIRM features are described in Table 3.2.

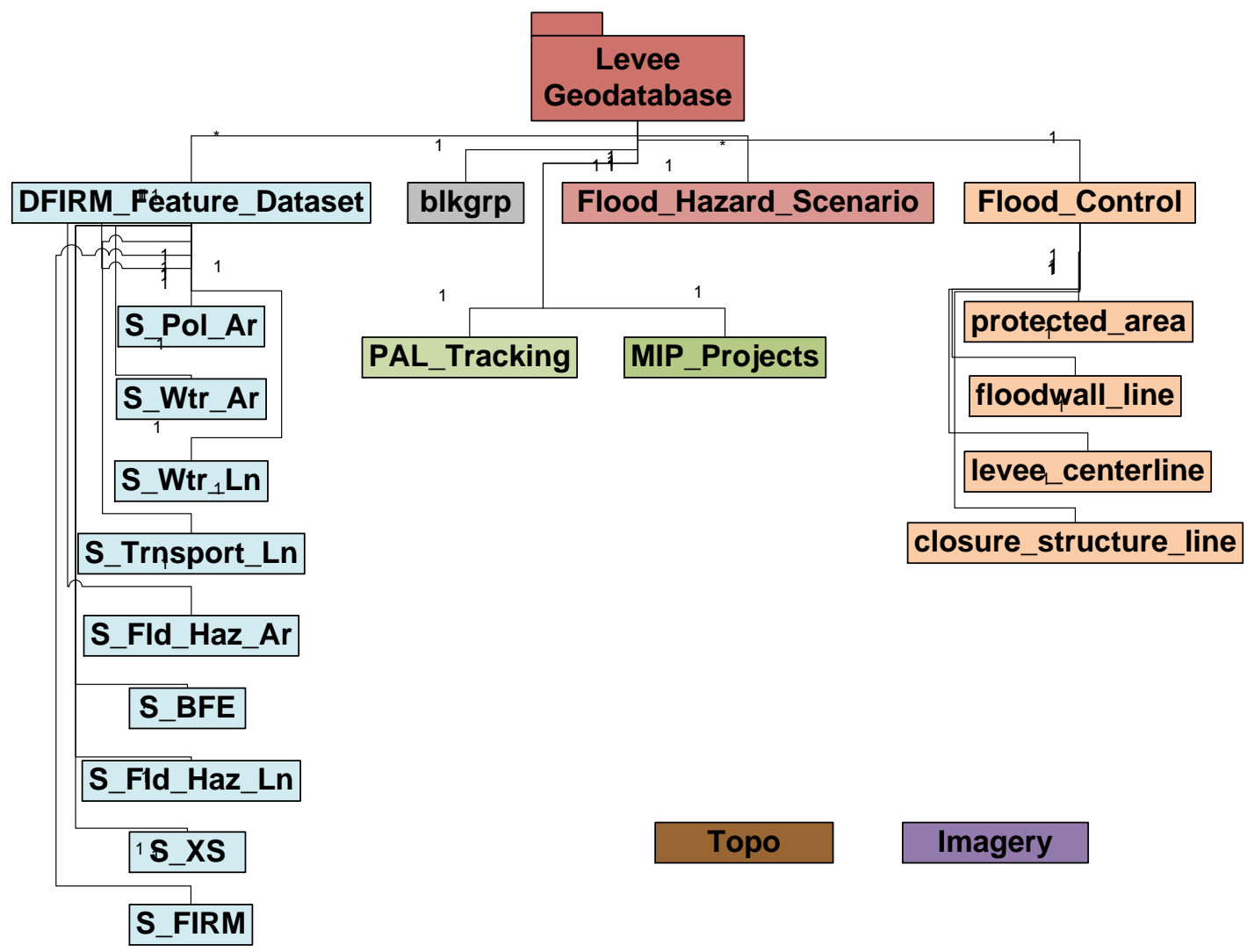

Figure 3.2 Geodatabase Conceptual Design Schematic

The Flood Control feature classes were designed to be stored in a Flood_Control feature dataset. The DFIRM feature classes were designed to be stored in a DFIRM feature dataset. The PAL_tracking table and MIP_Projects table will be imported individually into the geodatabase. The attributes required for each of the feature classes are listed by 
feature class in the following diagrams. Flood_Hazard_Scenario feature classes will be created to store the new scenarios created by the end users for the different scenario analyses. Table 3.2 provides a brief description of the feature classes, tables, and folders that are detailed in Figure 3.2 as part of the database design. 
Table 3.2 Description of Feature Classes, Tables, and Folders

\begin{tabular}{|c|c|c|}
\hline Feature Dataset & Feature Class & Description \\
\hline \multirow[t]{9}{*}{ DFIRM Feature Dataset } & S_Pol_Ar & Political Jurisdictions \\
\hline & S_Wtr_Ar & Lakes, Ponds, etc. \\
\hline & S_Wtr_Ln & Rivers, Streams, etc. \\
\hline & S_Transport_Ln & Roads, Railroads, etc \\
\hline & S_Fld_Haz_Ar & Flood Hazard Polygons \\
\hline & S_Fld_Haz_Ln & Flood Hazard Boundaries \\
\hline & S_BFE & Flood Elevations \\
\hline & S_XS & Model Cross-Sections \\
\hline & S_FIRM & $\begin{array}{l}\text { Flood Insurance Rate Map } \\
\text { Information }\end{array}$ \\
\hline \multirow[t]{4}{*}{ Flood Control } & levee_centerline & Levee centerlines \\
\hline & floodwall_line & Floodwall centerlines \\
\hline & closure_structure_line & Levee closures \\
\hline & protected_area & Areas protected by levees \\
\hline \multirow[t]{4}{*}{ No Feature Dataset } & Blkgrp & $\begin{array}{l}\text { Census information such as } \\
\text { population and housing }\end{array}$ \\
\hline & flood_hazard_scenario & $\begin{array}{l}\text { Areas inundated by particular } \\
\text { scenario flooding }\end{array}$ \\
\hline & PAL_Tracking & Tracking FEMA PAL Status \\
\hline & MIP_Projects & Tracking FEMA Mapping Projects \\
\hline \multirow{2}{*}{$\begin{array}{l}\text { Folders Outside } \\
\text { Geodatabase }\end{array}$} & Imagery & Aerial Raster Images \\
\hline & Topo & Topographic Raster Images \\
\hline
\end{tabular}




\subsection{User Interface Conceptual Design}

The user interface was designed to include four overall components using ArcGIS ArcCatalog and ArcMap. The first component is the geodatabase component for the system using ArcCatalog. The second component is the toolset component needed for the users to create the flood hazard scenario feature classes. The third component is a model component made up of the models that guide the end user through the different analyses specified in the requirements. The second and third components were designed to be saved in an MXD file for the application and used by ArcMap. The fourth component was the Map Production Component and was based on using the standard layout functionality of ArcMap to create the map outputs required by the end users. The four component concepts are detailed further below.

\subsubsection{Geodatabase Concept}

The first stage of using the system was to input the data into the system. This was designed to be accomplished through ArcCatalog which is shown in Figure 3.3. The conceptual design included Python Scripts to automate portions of building the geodatabase. These scripts were designed to be accessed using ArcCatalog through the ArcToolbox. The design also included using the standard import functions under the geodatabase options of the table of contents in ArcCatalog.

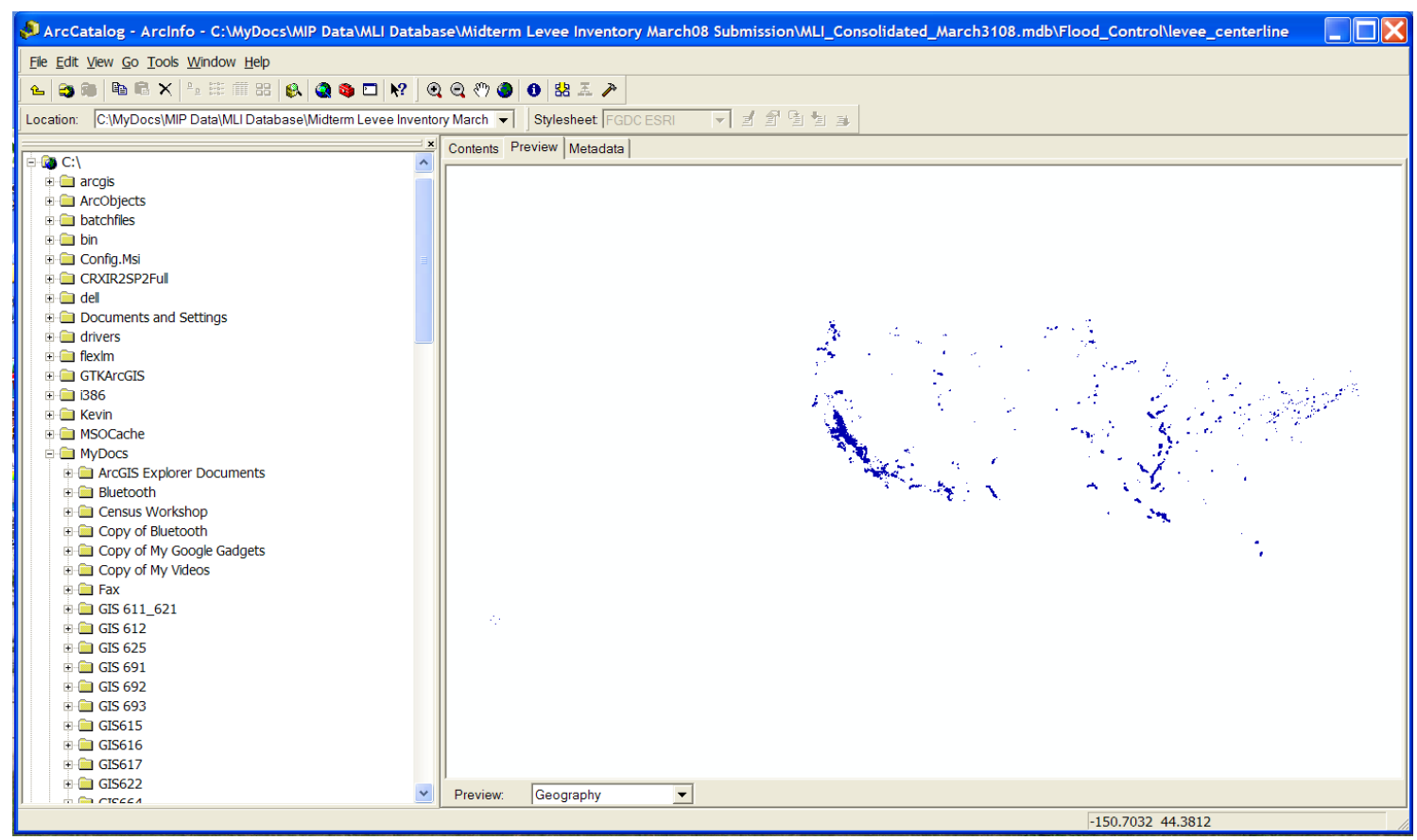

Figure 3.3 Screenshot of ArcCatalog Version 9.2

\subsubsection{Toolset Concept}

ArcMap was specified in the design to access the data in the geodatabase for editing and data creation. Figure 3.4 shows ArcMap Version 9.2 with the ArcToolbox open and 
some of the default toolbars along the application screen headers. A specialized set of tools will be developed to generate a toolbar to create the flood hazard scenarios for the application required for the impact analyses. The user can use the mouse and keyboard to interface with the software. All the standard tools and toolbars were left available to the end user.

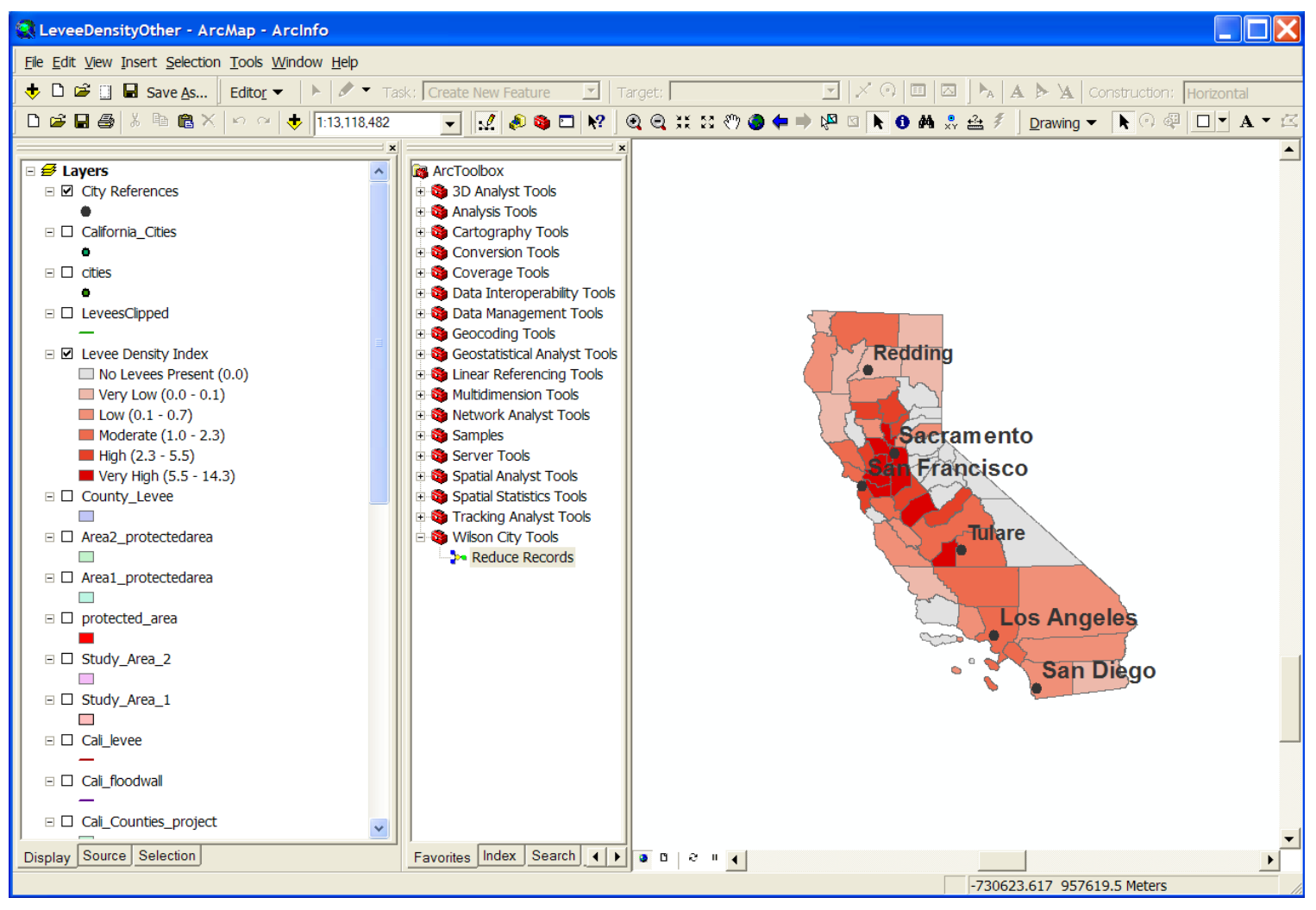

Figure 3.4 Screenshot of ArcMap Version 9.2 showing ArcToolbox

\subsubsection{Model Concept}

ArcMap was also used to perform the various analyses defined by the requirements.

Models were developed using Modelbuilder to automate the routine analyses necessary to produce the required results. These tools were stored in the application MXD in a Toolbox to be accessed by the end user through the ArcToolbox list. An example of an analysis that the user will perform is to calculate the number of household units impacted by flood hazard scenario as defined by the user. A model would be created similar to the example shown in Figure 3.5 below to perform the appropriate geoprocessing steps to calculate the results for the user. The model in Figure 3.5 represents a simple model that uses three inputs to create a new feature class. The user can define the parameters to be used by the model and then execute to generate the results. This is the same for all the models created for this application. 


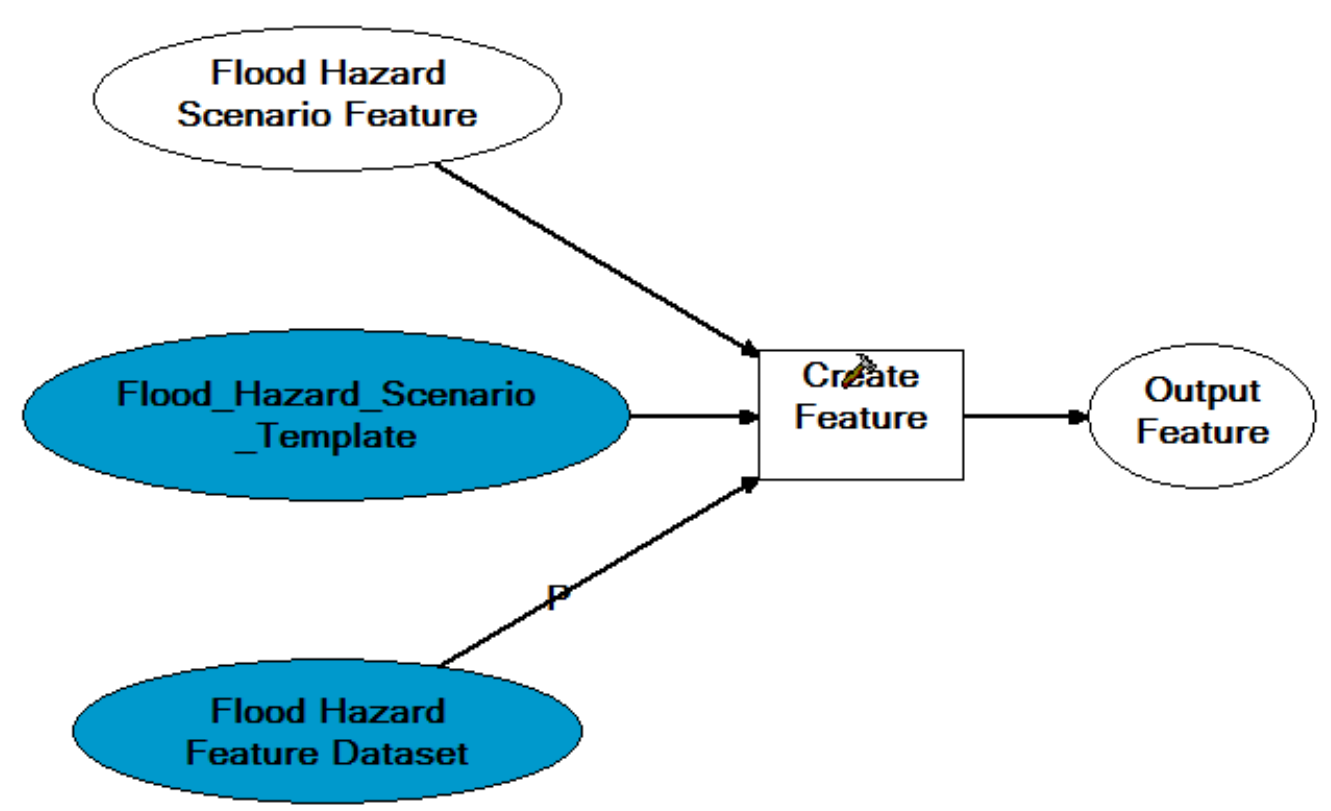

Figure 3.5 Example of a Model Created Using ModelBuilder

The expected models for this system are to:

- Determine which communities are impacted by the levee systems.

- Calculate the number of housing units impacted by the levee classifications and changes.

- Calculate the population impacted by the levee classification changes.

- Determine which FEMA mapping projects are impacted by a levee system and the status of those mapping projects.

\subsubsection{Map Production Concept}

ArcMap was specified to be used to generate the final map products. No special customization was deemed necessary for this component. The standard layout functionality of the software was determined to be sufficient to meet the needs of the end users. ArcMap will also produce the tabular results for the end user. These will generally be used in other software like Microsoft Word or Excel to include in reports and other documents. The software allows the user to create various sizes of maps as well as to export digital representations of the maps. 


\section{Implementation}

\subsection{Study Areas}

This application was designed to work anywhere in the continental United States. The datasets used for analysis, such as the Census Blockgroup data and the Levee Data, are national datasets. The DFIRM data is for the specific area of interest for their analysis. For implementation of this application, three counties were selected as study areas to develop the tools and test the geodatabase, toolset, and models. The selection was based on the presence of levees and different degrees of the complexity of the levees and flood hazards. The three counties are shown in Figure 4.1 and include Sacramento County, San Joaquin County, and San Bernardino County, California. Sacramento County and San Joaquin Counties were selected and set as Study Area 1 based on the high presence of levees, the complex flood hazards associated with them, and the fact that they are neighboring counties. San Bernardino County was set as Study Area 2 based on a lower presence of levees in the county and flood hazards that aren't overly complex. The application was implemented using the San Bernardino County data and then tested using the Sacramento and San Joaquin data. This helped to ensure that the application worked with different datasets other than the San Bernardino County data that was used to build the applications tools and models. 


\section{Study Areas for Application Implementation}
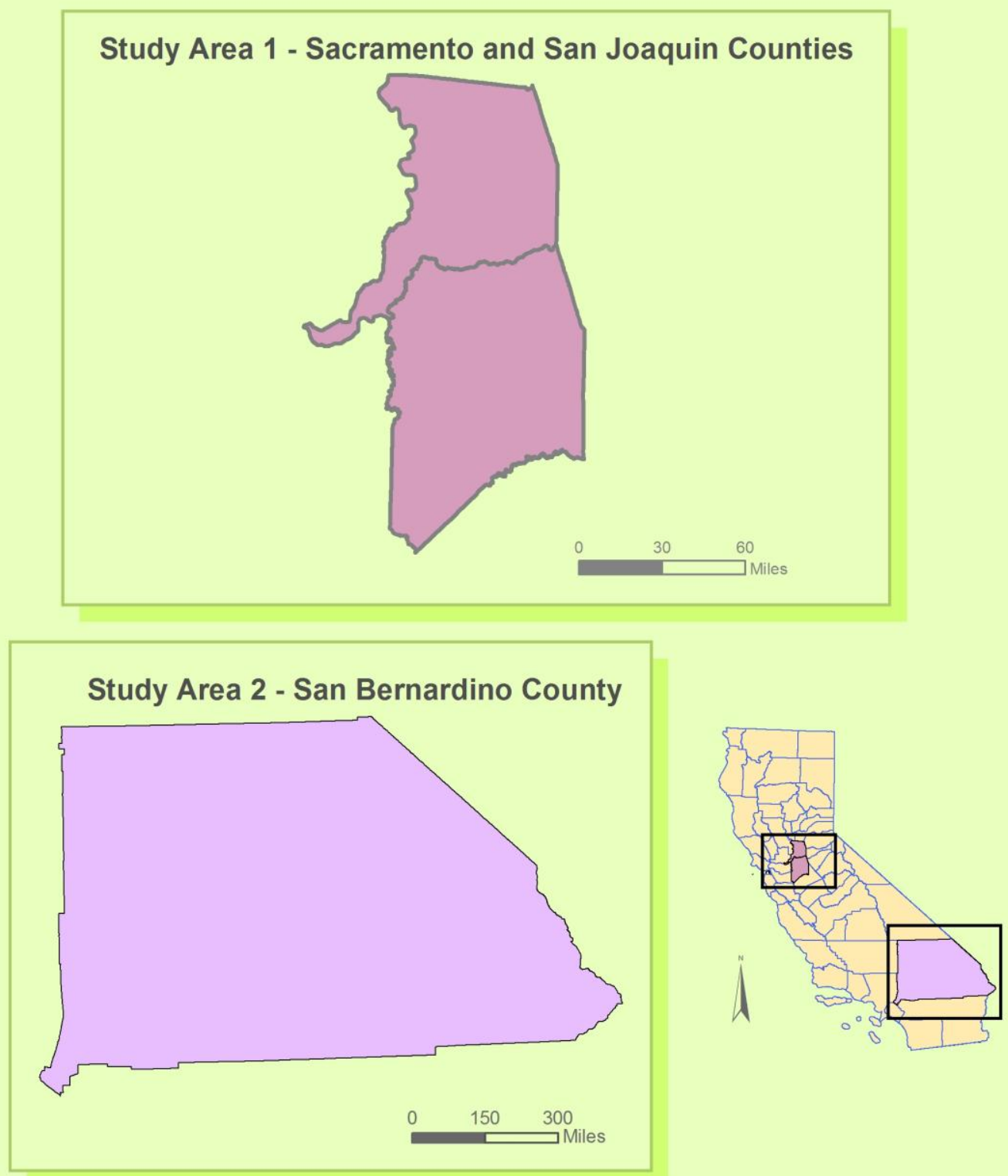

Figure 4.1 Study Areas for Application Implementation 


\subsection{Implementation Overview}

The implementation of the application involved the Geodatabase Implementation, Toolset Implementation, and Model Implementation. The three implementations were done in a parallel process since each of the three components build and interact with the other two components in the system.

As each component was being built, steps were taken to determine the impacts on the other components as well as changes to each component. The final application benefited from having this process of unit testing performed as the components were developed. This caused the application to be different from the conceptual design for the application. The implementation of the three components is detailed in the following sections along with the final build for the application of each component.

\subsection{Geodatabase Implementation}

The geodatabase implementation was the first component to be built as it is the foundation for the application. The geodatabase houses all the data to be used in the analyses, as well as the feature classes created by the user. The implementation of the geodatabase along with the other components in parallel showed some issues with the conceptual design of the system along with problems with the data being imported into the geodatabase.

The first issues to be encountered with the geodatabase involved trying to automate some of the data imports for maintenance purposes. This was conceptually designed to be done using Python Scripts, but further examination showed that the DFIRM data was not as consistent as originally thought. The DFIRM databases could be in a number of different projections and did not always include all the feature classes originally identified. The naming of the feature classes in each DFIRM database was also identical, which caused problems trying to import them into the geodatabase since after importing the first DFIRM feature classes, the system would not overwrite the already existing feature class in the geodatabase. These types of data issues made it necessary to explore other options for building the geodatabase such that it could be created and maintained as consistently as possible. ArcCatalog was found to be the best option using its existing functionality.

A file geodatabase titled Flood_Scenario was created in ArcCatalog to store all the data for the application. The overall geodatabase structure is shown in Figure 4.2. The national datasets were imported using the standard functionality of ArcCatalog under the file geodatabase. Most of the data being imported was either not projected or in a different projection than necessary for the application. Because the application was for the continental United States, the projection was specified as USA_Contiguous_Albers_Equal_Area_Conic which maintains the area of features for the user. Because the calculations to determine the population and housing units impacted are based on area, it was determined that area was the most important characteristic of the spatial data to maintain. The projection was specified as part of the import function for the Census Block Group, County, and State Features Classes. 


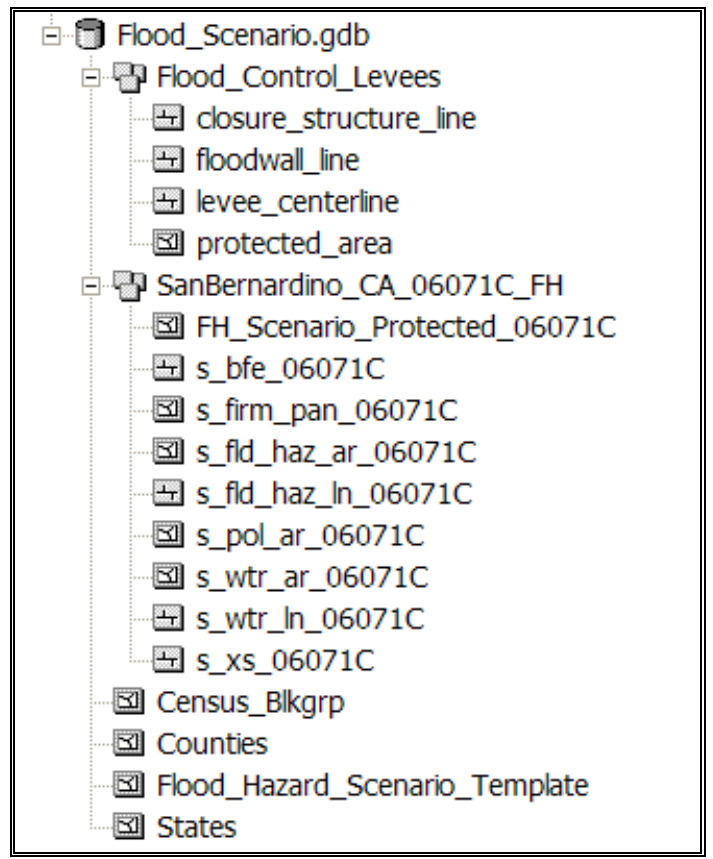

Figure 4.2 Overall Geodatabase Structure

The Census Block Group feature class was obtained from the ESRI 9.2 Dataset. Only the attributes of interest for this application were imported with the dataset. The population data for 2005 in the Pop2005 attribute field and housing unit data in the HSE_UNITS attribute field were the most critical data attributes for this application. Because the Shape_Area field is recalculated when the polygon features are clipped using the clip tool the model implementation required that a field be added to the feature class to capture the total area of each block group. A Total_Blk_Area field was added to the attribute table and the areas were calculated based on the original dataset so that the unaltered values could be used in later calculations no matter how the shape of the features had been altered.

The County and State Feature Classes were also taken from the ESRI 9.2 Dataset to be used for reference and orientation purposes in the application, and imported into the geodatabase using the same projection as the other data. The County feature class may also be used to perform joins with the tabular data using the County FIPS code attributes.

The feature classes for this application taken without any changes from the Midterm Levee Inventory (MLI) database were the levee_centerline, floodwall_line, closure_structure_line, and protected_area, which make up all the spatial features of a levee system for this application. The Flood_Control_Levees feature dataset structure is shown in Figure 4.3. The levee_centerline, floodwall_line, and closure_structure_line all have similar attributes. The main attributes for this application are the ones pertaining to the system identification, levee identification, and length. The protected_area feature class was added, as it may provide additional information to the user when defining their flood hazard scenarios for different levee classifications. The Flood_Control_Levees feature dataset was created using the USA_Contiguous_Albers_Equal_Area_Conic 
projection; the four feature classes were imported into the feature dataset. Storing all four of these feature classes organized them logically and separated the levee data from the other data that will be added to the database for the application.

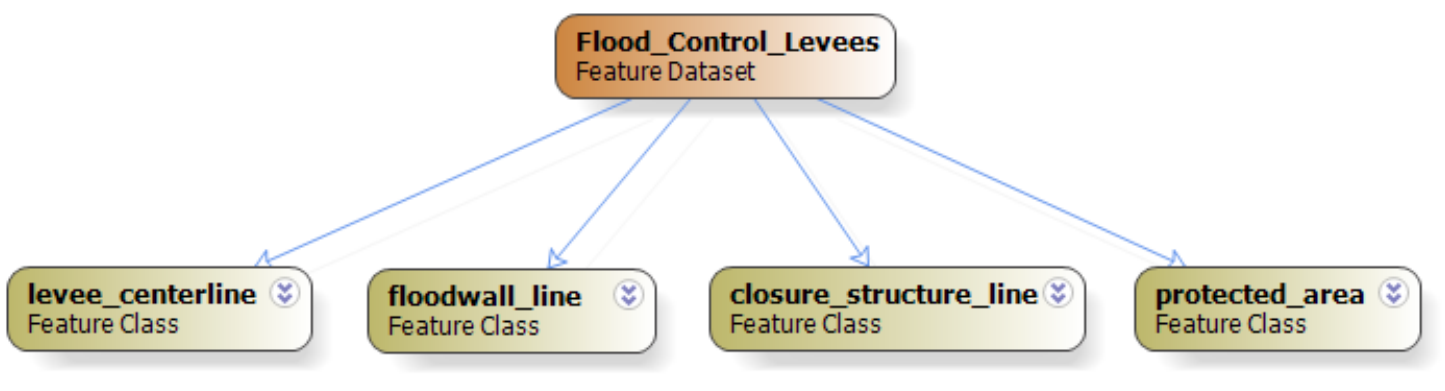

Figure 4.3 Flood_Control_Levees Feature Dataset Diagram

The DFIRM data for each countywide of community was conceptually designed to be imported into a single Flood_Hazard feature dataset, but due to the problems with importing files of the same name into the feature dataset, as well as problems with organizing and accessing the particular flood hazard data for each county, the design was changed to create a feature dataset to import the relevant feature classes of each DFIRM dataset. Usually the DFIRM for a county includes all the incorporated areas within that county. The feature dataset was implemented by naming the data after the county or, in some cases, communities that the DFIRM data covers. The countywide number assigned by FEMA is attached to the feature dataset at the end of the name of the feature dataset. The name is made up of the county name followed by an underscore the name of the state the county is located in and another underscore and the countywide number for that county. If the feature dataset is not a countywide, the FIPS code for the community is used as the end of the title of the feature dataset. The feature classes imported into the feature data also have this same six digit number assigned at the end of the feature class name. This solved the problem with the feature classes from the different DFIRM databases having the same name in the geodatabase. It also made it possible for the end user to relate the feature classes to the area of interest as they have the unique countywide number of FIPS number associated with them as the county or community being analyzed. A sample of the flood hazard feature dataset is shown in Figure 4.4 using San Bernardino County as the sample. The countywide number for San Bernardino, 06071C, was added to the Feature Dataset, as well as all the corresponding feature datasets to make them unique in the geodatabase and recognizable by the end user when added to ArcMap. 


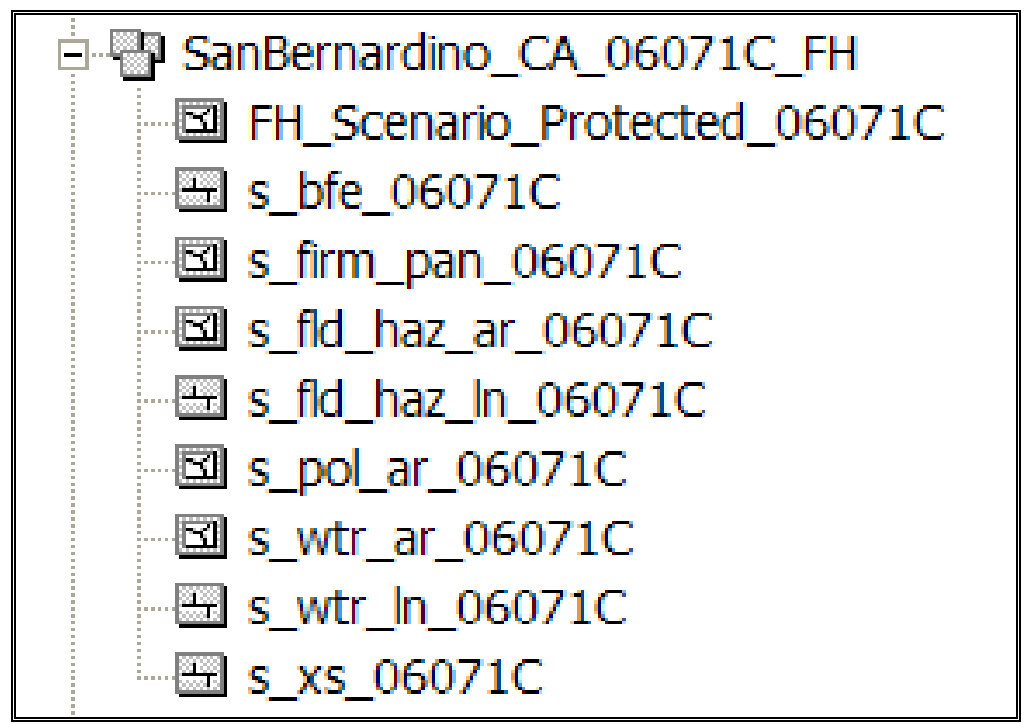

Figure 4.4 Sample Flood Hazard Feature Dataset

The feature classes implemented in the flood hazard feature datasets are listed in Table 4.1 . 
Table 4.1 Flood Hazard Feature Data Breakdown and Feature Class Descriptions

\begin{tabular}{|c|c|}
\hline \multicolumn{2}{|c|}{ Flood Hazard Feature Dataset } \\
\hline Feature Class & Description \\
\hline s_bfe & $\begin{array}{l}\text { Contains the line features with the water-surface elevations for the } \\
1 \text { percent annual chance flood. }\end{array}$ \\
\hline s_firm_pan & $\begin{array}{l}\text { Contains the polygon features for each of the Flood Insurance Rate Map } \\
\text { panels along with the identification number of all the panels in the set of } \\
\text { maps. }\end{array}$ \\
\hline s_fld_haz_ar & $\begin{array}{l}\text { Contains the polygon features for the flood inundation polygons for the } \\
\text { different types of flood zones identified by FEMA on the Flood } \\
\text { Insurance Rate Map. }\end{array}$ \\
\hline S_fld_haz_ln & $\begin{array}{l}\text { Contains the line features for the flood inundation zone boundaries } \\
\text { matching the polygon boundaries in the s_fld_haz_ar feature class. }\end{array}$ \\
\hline s_pol_ar & $\begin{array}{l}\text { Contains the polygon features for all the political areas in the DFIRM } \\
\text { data. This includes the county boundary and all the incorporated areas } \\
\text { within the county or the single jurisdiction political boundary. }\end{array}$ \\
\hline S_pol_ln & $\begin{array}{l}\text { Contains the line features for all the political areas in the DFIRM data. } \\
\text { This is the boundary line for all the political areas in the DFIRM data set. }\end{array}$ \\
\hline S_wtr_ar & $\begin{array}{l}\text { Contains the polygon features representing water features such as lakes, } \\
\text { ponds, ponding areas, and other water features that are best described by } \\
\text { polygons instead of line features. }\end{array}$ \\
\hline S_wtr_ln & $\begin{array}{l}\text { Contains the line features representing water features such as rivers, } \\
\text { streams, drainage channels, and other water features that are best } \\
\text { described as line features instead of polygon features. }\end{array}$ \\
\hline S_Xs & $\begin{array}{l}\text { Contains the line features representing the cross-sections used in } \\
\text { hydraulic models to determine the water-surface elevations of the } \\
\text { specific flood events being mapped. They are generally perpendicular to } \\
\text { the flow of the flooding and have the attributes that are taken from the } \\
\text { model results. }\end{array}$ \\
\hline
\end{tabular}

The feature classes described in Table 4.1 were implemented in the flood hazard feature dataset to enable the analysis and to assist the user in defining the flood hazards in the flood hazard scenarios. 
The template for the flood hazard scenario polygon feature class was the last feature class implemented in the geodatabase. This template created the different flood hazard scenarios that the end users define for analysis. The scenarios will be named by the user and stored in the county or community flood hazard feature dataset. The main attributes of the Flood_Hazard_Scenario_Template are described in Table 4.2.

Table 4.2 Flood_Hazard_Scenario_Template Main Attributes

\begin{tabular}{||l|l||}
\hline \multicolumn{2}{||l||}{ Flood_Hazard_Scenario_Template Feature Class } \\
\hline \hline Field & Field Description \\
\hline FLD_ZONE & $\begin{array}{l}\text { Denotes the specific flood zone as defined by FEMA for the flood hazard } \\
\text { polygon. The flood zone describes the type of flooding represented by } \\
\text { the polygon and also the flood frequency being depicted such as the } 1 \\
\text { percent annual chance or the 0.2 percent annual chance flood. }\end{array}$ \\
\hline SFHA_TF & $\begin{array}{l}\text { Denotes whether the flood polygon is a Special Flood Hazard Area or an } \\
\text { area of inundation by the 1 percent annual chance flood }\end{array}$ \\
\hline SHAPE_Area & Captures the area of the polygon feature \\
\hline
\end{tabular}

The excel tables containing information about the FEMA's Provisionally Accredited Levees and flood hazard mapping projects were added to the geodatabase by importing the sheets with the information from each excel spreadsheet separately. The Provisionally Accredited Levee table was added as PAL_Tracking to the geodatabase and the flood hazard mapping project table was added as Study_Tracking. Having access to these two tables allows the user to look up information and perform table joins if needed for further analysis.

The implementation did not account for problems with setting the projections for areas outside of the continental United States, such as Alaska, Hawaii, Puerto Rico, Guam, etc. If the application is used for these areas the projection could be changed in the layout view for representation purposes. The projection set to the USA_Continguous_Albers_Equal_Area_Conic does not interfere with any analyses for these areas. It would only cause problems for the user in dealing with the alignment of the areas, as they may not appear as the user is used to these areas being represented on maps or in other datasets without changing the projection to correct for this in the data frame.

The topographic and aerial photograph rasters were not implemented in the geodatabase itself. Instead they are stored outside the geodatabase in the application folder under the 
folder titled topo_imagery with subfolders, created to organize the data as shown in Figure 4.5. The subfolders are titled by the state, followed by the county or community name, and added by the user as necessary. This allowed for the large raster datasets to be added to the system without making the geodatabase too large.

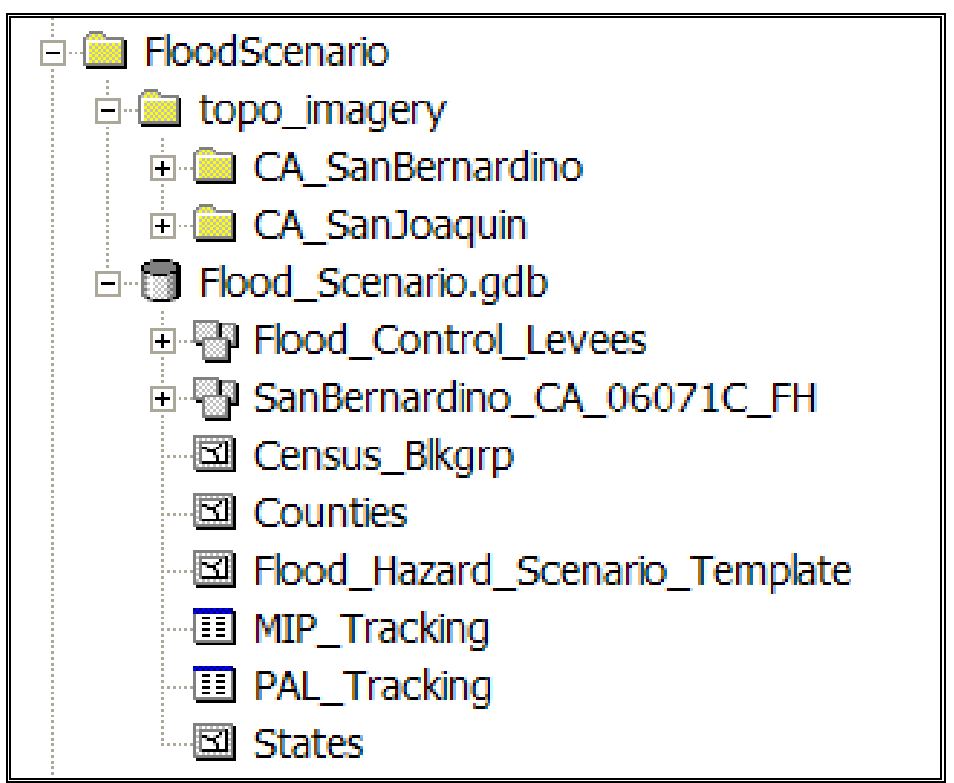

Figure 4.5 Implemented Application Geodatabase and Folder Structure

\subsection{Toolset Implementation}

The implementation of the Toolset required that a workflow of the process to define the flood hazards for the specific flood hazard scenario be developed. The tools would then be set up to follow this process and allow the user to go through the same process using a GIS. The tools were implemented in ArcMap in parallel with the geodatabase and model implementations such that changes were made as the tools were created to ensure that they worked optimally with the implementation of the other two components.

\subsubsection{Flood Hazard Scenario Workflow}

The implementation of the toolset depended on a clear workflow process to create the flood hazard scenarios. The process also depended on the data that is available to the end user for the area to be analyzed. It was assumed that as part of the design and implementation of the toolset that the end user will be a member of the Engineering Management Section of FEMA, and that they have the domain knowledge and expertise to define the flood hazard scenarios with the data available through this system. No hydrologic or hydraulic analyses were implemented as part of this application. The results of these types of analyses are present in the DFIRM data produced by FEMA where available. 
The process was implemented using ArcMap with the Flood Hazard Scenario MXD open to access the toolbars created for the Create Flood Hazard Scenario activity. The user added the specific DFIRM data features from the county or community feature class to the geodabase using ArcCatalog prior to starting this process. The user would also add topographic data, such as a Digital Elevation Model, as well any imagery data through ArcCatalog so that it could be used through this MXD in ArcMap to assist with the creation of the flood hazard scenarios. As part of this implementation, the online imagery available from ESRI was added to the MXD to make it available to the user anywhere in the United States. The ESRI_Imagery_World_2D was selected, as it offers high resolution imagery for the United States. This allows the user to use imagery for areas where the user does not have any imagery data available and will help alleviate the need to obtain and load new imagery data for this type of analysis.

A Use Case was created and shown in Table 4.3 to determine the workflow involved in defining a flood hazard scenario and to create the toolbars for the Toolset Implementation. 
Table 4.3 Create Flood Hazard Scenario Use Case

\begin{tabular}{|c|c|}
\hline Use Case Name: & Create Flood Hazard Scenario \\
\hline Description: & $\begin{array}{l}\text { Describes the process the Engineering Management Branch staff } \\
\text { use to create the necessary flood hazard data to perform the } \\
\text { analyses. }\end{array}$ \\
\hline Actor: & Engineering Management Branch staff \\
\hline Trigger & $\begin{array}{l}\text { External - Staff will launch the system and work with the tools to } \\
\text { create the Flood Hazard Scenario associate with the levee system of } \\
\text { interest. }\end{array}$ \\
\hline Major Inputs: & $\begin{array}{l}\text { DFIRM database data, Flood Control (Levee) data, Digital } \\
\text { Elevation Models (DEM) (optional), Aerial Imagery Data } \\
\text { (optional), User defined Flood Hazard Areas }\end{array}$ \\
\hline Major Outputs: & $\begin{array}{l}\text { Data defining the flood hazard areas associated with a specific } \\
\text { levee protection scenario. }\end{array}$ \\
\hline Normal Process Steps: & $\begin{array}{l}\text { 1. User selects Develop Levee Flood Hazard Scenario } \\
\text { 2. Allow the user to select the data to be displayed for the area of } \\
\text { interest. } \\
\text { 3. Based on the data available, the user may: } \\
\text { a. Select the polygons from the s_fl_haz_ar feature class } \\
\text { b. Create contours from available DEMs } \\
\text { 4. User modifies polygons as necessary if they were selected. } \\
\text { 5. User delineates the flood hazard areas based on the available } \\
\text { data and contours developed from the DEM. } \\
\text { 6. User develops the flood hazard areas for the scenario being } \\
\text { developed using steps } 3,4 \text { and/or } 5 \text {. } \\
\text { 7. User saves the completed scenario data. }\end{array}$ \\
\hline $\begin{array}{l}\text { Alternative Process } \\
\text { Steps: }\end{array}$ & $\begin{array}{l}\text { 1. User may save the scenario data before it is completed to } \\
\text { continue working later. }\end{array}$ \\
\hline Preconditions: & Data from all the sources has been loaded into the database. \\
\hline Post-condition: & $\begin{array}{l}\text { Flood Hazard Scenario for a specific levee protection scenario } \\
\text { created. }\end{array}$ \\
\hline Assumptions: & $\begin{array}{l}\text { Engineering Management Branch staff have knowledge of how the } \\
\text { flood hazards should be defined. }\end{array}$ \\
\hline
\end{tabular}

\subsubsection{Developing the Toolset}

Based on the Use Case, the next step in the Toolset Implementation was to determine what tools would be required to implement the process in ArcGIS. A survey of the tools available in the ArcGIS system showed that the workflow described in the Use Case could be achieved without creating any custom tools. The existing tools and functions included in ArcMap would be sufficient to create the toolbars necessary to walk the user through creating the flood hazard scenarios in ArcMap. 
Using ArcMap, the custom toolbars were created using the VBA included with the software. This was done through the Customize Command Box of the Toolbars. The various tools were selected and added to the toolbar to make them readily available to the end user in an easy to access manner, with the tools ordered logically to match the process for defining the flood hazard area polygons. Two new custom toolbars were created to help alleviate any confusion.

The first toolbar created was the Terrain and Topo toolbar shown in Figure 4.6. This toolbar was created to generate contours from a DEM. Create Hillshade and Create Slope were also buttons added to this toolbar. It is optional for this process and only needed if the user wishes to use a DEM to define the flood hazard areas for the scenario being created.

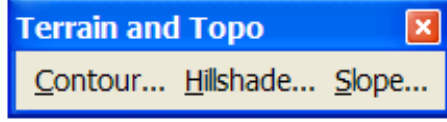

Figure 4.6 Terrain and Topo Toolbar

One of the first steps was to create the new feature class using the Flood_Hazard_Scenario_Template feature class found in the ArcToolbox under the Data Management Tools as the template. The Create Feature Class tool was brought into ModelBuilder and the tool was customized to create flood hazard scenarios based on the template feature class. Customizing the tool using ModelBuilder changes the tool into a model. The model was added to the Flood Hazard Scenario Toolbox which was created to store the analysis models during model implementation. This model is show in Figure 4.7 and highlighted by the shaded blue box. Customizing the tool reduces the level of effort required by the end user and makes creating the feature class very straightforward. The modifications to the tool resulted in the end user needing only to select the location or feature dataset for the new feature class to be stored and the name of the new feature class. This step may not be necessary based on how the user creates the new flood hazard scenario feature class, but it is needed when the new feature class is created manually by an end user using the sketch tools to delineate the polygons for the flood hazard areas. 


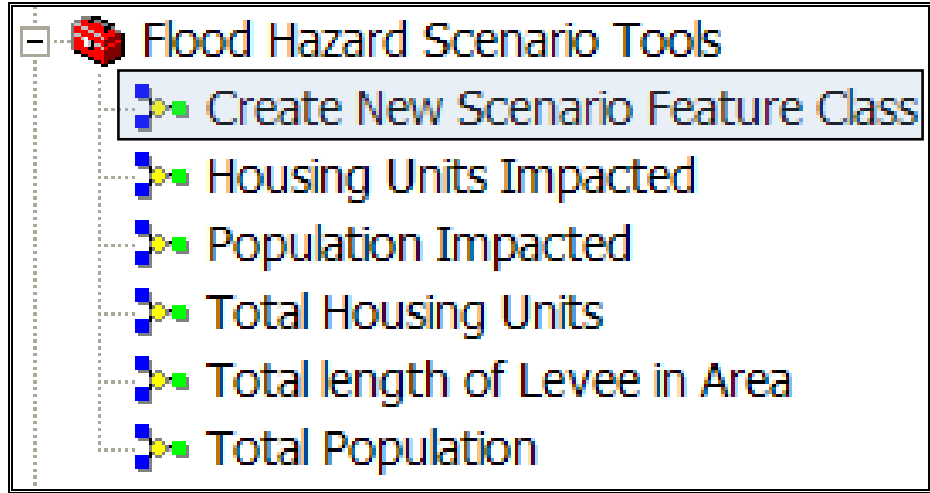

Figure 4.7 Create New Scenario Feature Class Model in the ArcToolbox

The main toolbar was the Flood Hazard Scenario Creator toolbar see Figure 4.8 as implemented in the application. The purpose of this toolbar was to give the end user all the tools needed to create the specific flood hazard scenario in order to perform analyses using ArcMap.

\section{Flood Hazard Scenario Creator

Figure 4.8 Flood Hazard Scenario Creator Toolbar

The Editor functions were also needed for the creation of new flood hazard scenario feature classes, but adding the entire functionality of the Editor Toolbar to this toolbar would have made it too complex for the end user. It was decided that the Flood Hazard Scenario Creator toolbar would include a few functions that would tie it to the editing process and at the same time allow the user to use the commonly used Editor Toolbar already existing in ArcMap. This would aid making the users more familiar with ArcGIS. The buttons added to the toolbar for the editing process were six tools from the ArcToolbox. The first was a toggle for the Editor Toolbar itself. This button calls the Editor Toolbar for ArcMap. The other five buttons do duplicate some of the functionality of the Editor Toolbar but were thought to make the process easier for the end user. The Start Editing, Save Edits, Stop Editing, Sketch Tool, and Edit Tool were added to the Flood Hazard Scenario Creator toolbar to make the workflow of the toolbar more logical. The Editor Toolbar would still be necessary to set the target feature class for editing, but having the buttons on the toolbar would make the editing more efficient while the user is working on defining the flood hazard polygons.

The next set of tools added to the toolbar was for selection based on the existing flood hazard data from the DFIRM data or from the Midterm Levee Inventory data. The 
existing flood polygons in the datasets may be appropriate to approximate the flood hazard scenario that the end user wishes to create.

The Set Selectable Layers button. As the toolset was being developed and unit tested it became clear that selecting multiple polygons was made more difficult because other features in other feature classes were being selected as the user mouse clicked through the polygons. The solution for this problem was to add the Set Selectable Layers Button to the toolbar so that the end user could specify which feature class they were performing the selections from in the Table of Contents.

The Select Features button allows the end user to select the flood polygons that are to be used in the flood hazard scenario feature class. The implementation of this tool requires the end user to hold the shift key while using the mouse to select the polygons for the new feature class. Once the polygons are selected, the end user creates a new feature class based on the selection as the new feature class or the feature class to be modified to become the flood hazard scenario feature class. This is done by creating a layer based on the selection and then, if satisfied with the features in this layer, converting that to a feature class by using the Data Export function. This step bypasses the need to use the Create New Scenario Feature Class tool that was created for cases when the end user wishes to begin delineating flood hazard polygons without performing selections from the existing data or the data does not exist.

The Select Features by Attribute button. This tool allows the user to select the flood polygons based on an attribute of the polygons. This was implemented to be the FLD_ZONE attribute of the s_fl_hz_ar feature class. The end user may select the type of FLD_ZONE they wish to use for the new feature class for the flood hazard scenario. This was implemented to be a separate option from the Select Features tool, but the two may be used together to add to the selection of flood hazard polygon features until the desired features have been selected to export into the new feature class for the desired scenario.

The Clear Selected Features button makes it easy to clear all the selected features from either of the two selection methods added to the toolbar. This would be the easiest way for the end user to start a new selection or discard the current selection.

The last button added to the toolbar is the Attribute Editor button. This button allows the user to perform edits on the attributes of a feature while in editing mode. The end user may wish to change or view the attributes of a single feature and this button allows quick access to the attributes of a single selected feature. The user may also still make edits to the features of a feature class using the attribute table. 
The Flood Hazard Scenario Creator toolbar, Editor toolbar, and the Terrain and Topo toolbar, along with the Create New Scenario Feature Class tool, make it possible for the end user to use ArcMap to create a feature class of polygons to define the areas which would be inundated based on the flood scenario they wish to portray. The attributes of the feature class may be edited to keep the data clean and consistent but is optional, based on how the feature class will be used for the analyses. The attributes are not key to the models created to carry out the analyses.

The overall customized interface that contains the three toolbars discussed above is depicted in Figure 4.9. The implementation of the toolset was carried out using existing ArcMap tools; no custom tools were coded to create the functionality necessary to meet the requirements of the application. This precluded the use of ArcObjects and only the VBA included with the ArcGIS software was used to create the new toolbars and add the tools from the existing set of tools. The toolset was saved as part of the MXD for the application. This implemented toolset allows the user to develop flood hazard scenarios for any situation, not just those associated with levee classifications, although that was the original intent of the application.

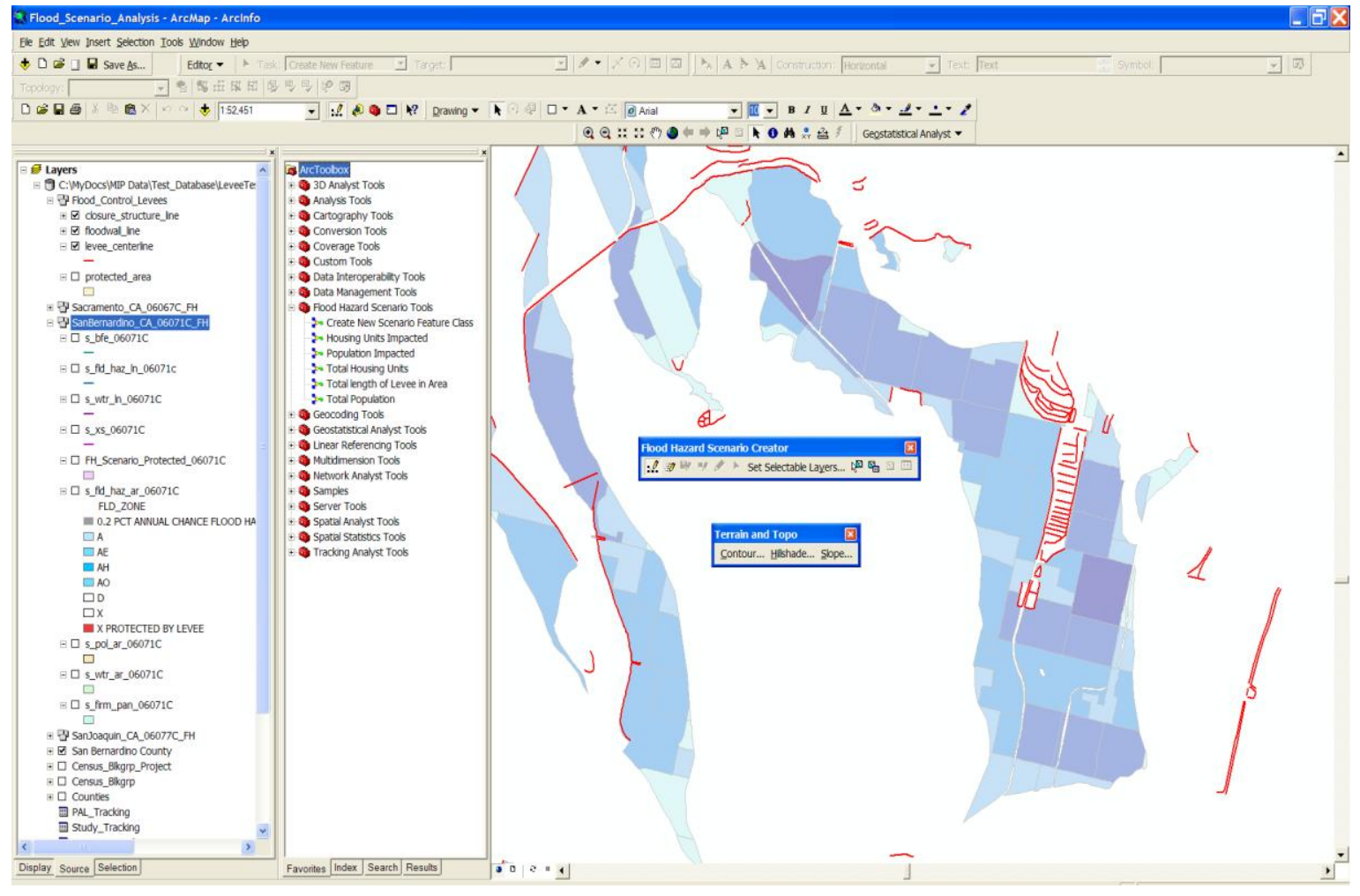

Figure 4.9 Implemented Flood Hazard Analysis MXD in ArcMap Showing Toolbars 


\subsection{Model Implementation}

The implementation of the analysis portion of the application was done using the tools in ArcToolbox and ModelBuilder. Several analyses were required as part of the requirements and throughout the implementation, other tools were deemed necessary and added to the set of models created for the application. Five models were developed to perform routine analyses for flood hazard scenarios. The data required for these analyses was implemented through the geodatabase implementation or created using the toolsets described in the toolset implementation.

\subsubsection{Model Overview}

The requirements for the application stated that several analyses would be required to generate specific results for flood hazard scenarios. Throughout the implementation it was found that some of the answers could be determined by simple attribute queries of tables while others required geoprocessing to calculate a final result. The five models implemented calculated the population of an area, population impacted by a specific flood hazard scenario, housing units of an area, housing units impacted by a specific flood hazard scenario, and the total length of levees in a given area. The areas were defined for this implementation as political areas which can either be taken as counties from the County feature class, or smaller political units defined in the s_pol_ar feature class from the DFIRM data. These models provide the results to the most commonly asked questions of FEMA's staff regarding areas where flood hazard mapping is being done or levee classifications are changing. The implementation of these models allows for the analysis of any flood hazard scenario the user wishes to develop, not just those associated with levees and their classification changes.

\subsubsection{Developing the Models}

Implementation of the five models required using ModelBuilder to chain together the necessary tools and set the necessary parameters for each process. The implementation also required that help text be added to assist the end user with understanding what was being asked of them in the dialog box for each model. This was all done using ModelBuilder in ArcMap Version 9.2. The five models are available under the Flood Hazard Scenario Tools toolbox created for this application. The toolbox is shown in Figure 4.10, with the five analysis models highlighted by the blue shaded box. 


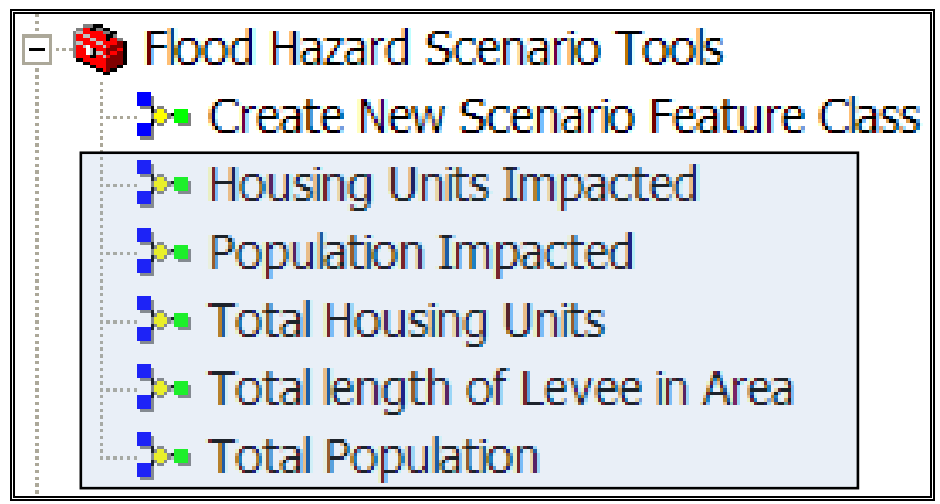

Figure 4.10 Flood Hazard Scenario Toolbox

The first model was the Population Impacted model shown in Figure 4.11 and was created to calculate the population impacted by a given flood hazard scenario based on the feature class created to represent that scenario. Inputs in the model were the Blkgrp feature class and the flood hazard scenario feature class. The model was implemented by using the flood hazard scenario feature class to clip the Blkgrp feature class using the Clip tool. This results in only the portions of the block groups that contained within the flood hazard scenario feature class polygons to be retained. The user specifies the name of this resulting new feature class and where it is stored using the model's dialog box. The model was implemented such that the user specifies which flood hazard scenario feature class to use for the geoprocessing. The new clipped feature class then has a field added using the Add Field Tool from ArcToolbox. The field is named Impacted_Pop and is calculated based on the ratio of the area of the clipped census block group polygon compared to the total area of the original census block group polygon. This ratio is multiplied by the Population of that census block group polygon reported for 2005 to calculate the population that is within the clipped polygon. This assumes that the population distribution is uniform across the polygon. The clipped polygon Impacted_Pop attributes are summed for all the polygons in this new feature class and reported to the end user using the Summary Statistics tool in ArcToolbox through a table. The table is added to the Table of Contents in ArcMap with the Total Population Impacted value.

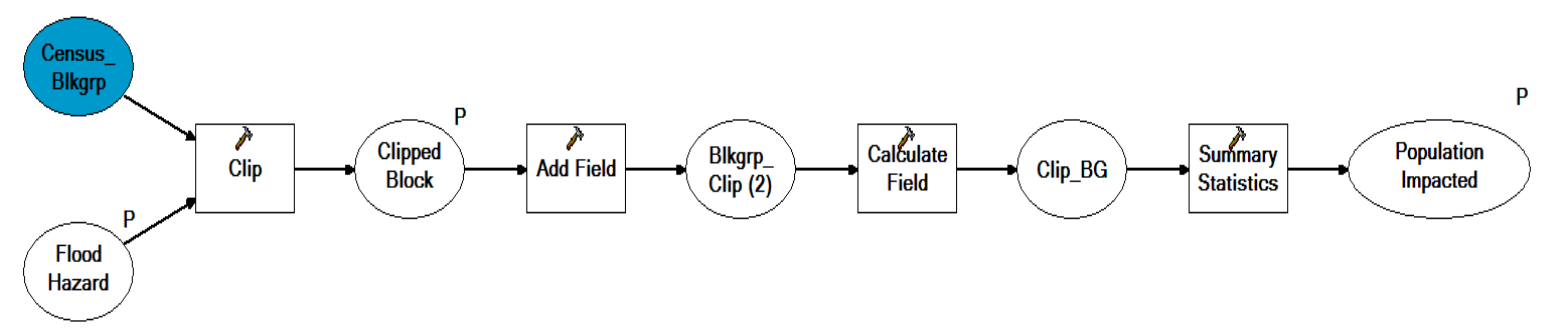

Figure 4.11 Population Impacted Model Diagram

The second model was the Total Population model shown in Figure 4.12. This model was created to calculate the total population for an area and was initially implemented to account only for the population at the county level, but later changed to more closely 
follow the logic of the Impacted Population model to be able to calculate the area of any political areas based on the polygon(s) for that area(s). This made the model much more flexible and the results more applicable to questions about particular municipalities, rather than just the county level. Flood hazard scenarios could then be analyzed and compared at the community level rather than only on a county level. The purpose of this model was to put the results of the Population Impacted model in perspective and give them some relevance. The model was implemented so that the user specifies the parameters of which political area feature class to use for the geoprocessing, where the data is to be saved, and what the new clipped feature class would be named. The same tools were used as the Population Impacted, with the same ratio type calculation of population using the clipped polygon areas. The results are also computed using the Summary Statistics tool which generates a table with the total accumulated population for all the block groups contained within the political areas polygons. The difference between this model as implemented and the Population Impacted model is the input feature class being the political areas feature class. The Blkgrp feature class input is the same as in the Population Impacted Model.

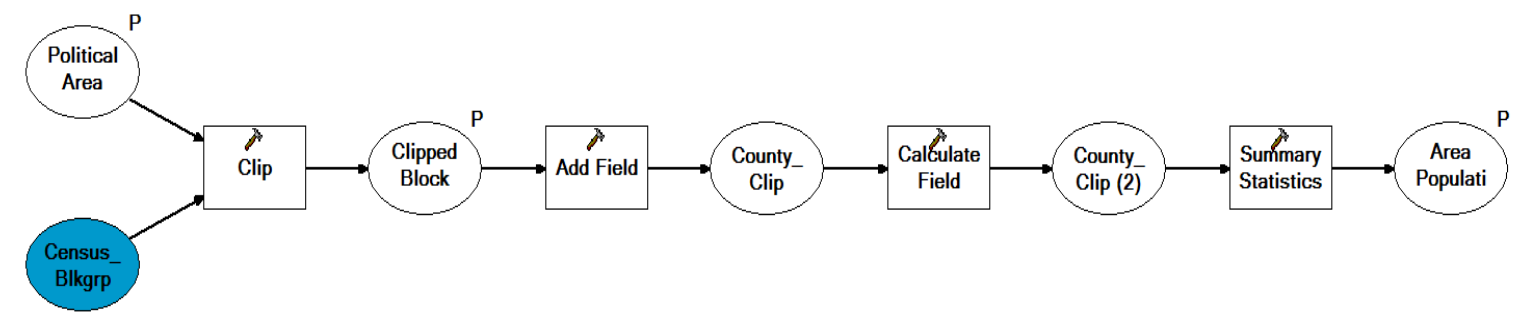

Figure 4.12 Total Population Model

The third model to be implemented was the Housing Units Impacted model. This model was created using the Population Impacted model as a template for all the processes and calculations since the inputs are the same only the attributes used for the calculations change. The attribute of HSE_UNITS was used to calculate the number of housing units impacted by the user-specified flood hazard scenario feature class. The flood hazard scenario feature class was set as a parameter in ModelBuilder, along with the storage location of the new clipped feature class and the name of the new feature class. The same tools were used in this model as in the Population Impacted model. The Blkgrp feature class is clipped using the Clip tool. A field is added titled Impacted_Units which is then calculated using the Calculate Field tool to take the ratio of the clipped block group polygons multiplied by the housing units for that polygon. The same assumption of uniform housing unit distribution throughout the polygons was applied to this model, as with the population in the two population models. The Summary Statistics tool was used to calculate the number of housing units for all the polygons included in the clipped feature class and is reported to the user in a table which is added to the ArcMap Table of Contents. The output for the user is shown in the Figure 4.13. 
再 Attributes of HU_Impacted

\begin{tabular}{|c|c|c|c|c|c|}
\hline OBJECTID $^{*}$ & FREQUENCY & SUM_Impacte & Units & & \\
\hline 1 & 188 & & 2.193221 & & \\
\hline Record: 14 & $1 \cdot$, & Show: All & Selected & Records ( 0 out of 1 Selected) & Options - \\
\hline
\end{tabular}

Figure 4.13 Results of Housing Units Impacted Model

The fourth model was similar to the Total Population model in that it was implemented to calculate the total housing units for an area. This is parallel to the total population processing in that the model uses a user specified political area polygon feature class which is a parameter to clip the Blkgrp feature class using the Clip tool. The location and name of the feature to be stored were both set as parameters in the model for the user to specify through the model dialog box. The same guidance information was added to the dialog box as with the other models to explain what information the user is expected to enter in those fields. The new clipped feature class had a field added to the attribute table titled Housing_Units. The Calculate Field tool was then used to calculate the value for each feature using the same area ratio as the other models multiplied by the housing units for that particular block group. The Summary Statistics tool was again used to sum the total number of housing units back on the Housing_Units field. The same assumption of uniform housing unit distribution for all the polygons was applied to this model.

The last model was implemented based on use of the application and anticipating future questions posed to the users and the application. The Total Length of Levee in Area model is shown in Figure 4.14. The total length of levees in a given political area was thought to be a potential question that the application could easily calculate results to answer. The feature classes of floodwall_line, levee_centerline, and closure_structure_line were used as the set inputs into the model. The political areas feature class to define the area for the calculation was set as a parameter for the user to specify in the model dialog box. The title of the table with the final results of the model was also set as a model parameter for the user to enter in the model dialog box. The floodwall_line, levee_centerline, and closure_structure_line feature classes were merged in to one feature class for this analysis using the Merge Tool. This created one feature class with the features and attributes of each of the line classes. The merged feature class was clipped using the Clip tool and the political area feature class as the bounding areas. The clipped merged levee feature class was then used to calculate the total length of the line features contained in the clipped feature class. This resulted in a length of meters for the line features. The Calculate Field tool was then used to convert the length in meters to miles for easier use by the end user. The model dialog box had information that the results would be in miles in the table. The model did not allow units to be shown in the table so they were not added as an attribute to the clipped feature class as that would have added confusion since those values were in meters. 


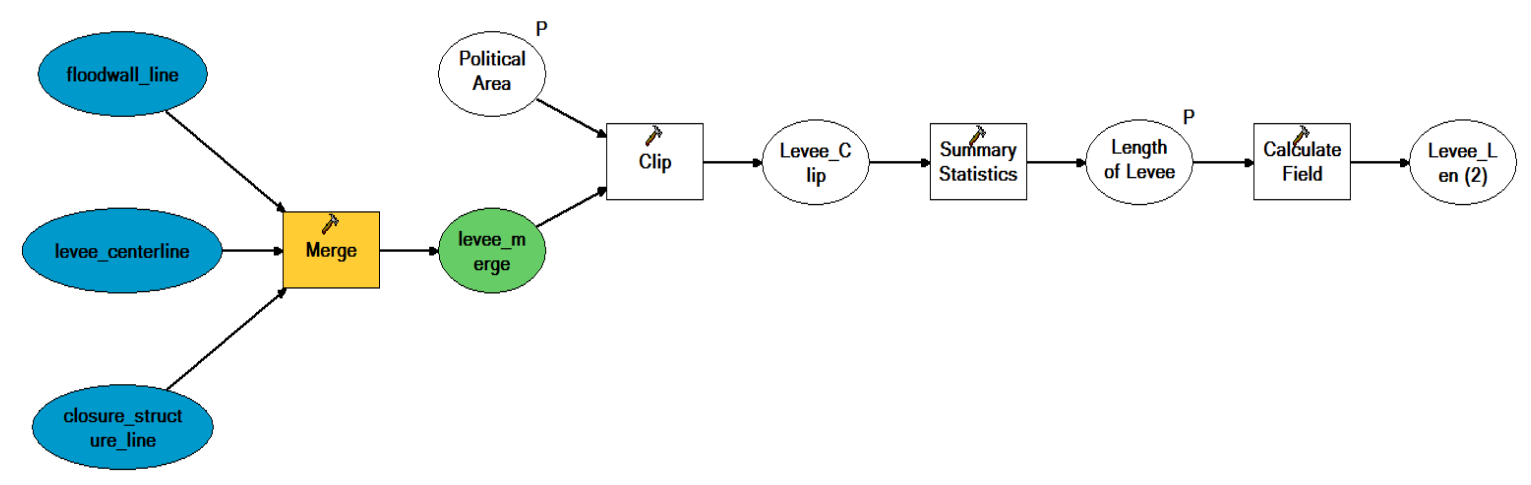

Figure 4.14 Total Length of Levee in Area Model Diagram

The other analyses specified in the requirements did not require models to be developed. Determining which mapping projects were in a certain county was a simple matter of a select by attributes function in the attribute tables options. A table join with the County feature class could also be done to provide some additional analytical power through the use of the spatial component to the Study_Tracking table to answer other questions that may be posed to the end user. The same applied to the PAL_Tracking table. The county FIPS code would be used for both of these tables to perform a join to the County feature class.

\section{Testing}

Testing of the implemented application involved testing of the geodatabase, the toolset, and the models. Ensuring that each of the components functioned properly in the final implementation was critical to successful delivery of the final application. The client was not available for testing so other individuals were solicited to test the final application. They were not part of the Engineering Management Branch but with one-on-one training were able to understand the goals of the application and the methods used to implement them through this application. The final implemented components were tested through a simulated exercise with the study area data.

\subsection{Testing the Geodatabase}

The testers were asked to update portions of the geodatabase based on the steps used to import the DFIRM data and the tables into the geodatabase. A new feature dataset was created for Sacramento County and all the feature classes necessary from the DFIRM data were successfully renamed and imported into the geodatabase. The tables from the PAL_Tracking and Study_Tracking spreadsheets were also added to the geodatabase successfully.

Testing of the Toolset and the Models also resulted in the data being available to ArcMap without any complications or restrictions once the locks placed on the data by ArcCatalog were removed when the feature classes were not being used by both ArcMap and ArcCatalog which is a standard issue encountered by ArcGIS users as a precaution. 
The geodatabase was only tested on a standalone PC and was not tested on a network server with multiple users accessing the geodatabase.

\subsection{Testing the Toolset}

The testers were able to walk through the creation of a flood hazard scenario feature class after being shown through the process one-on-one without difficulty. The testers used manual delineation of the flood hazard polygons in a new feature class created using the Create New Scenario Feature Class tool, as well as creating a new feature class based on the selection tools and the Sacramento DFIRM data which had been imported into the geodatabase during the testing of the geodatabase.

The resulting feature classes were valid for use in the models during the testing of the models and the attributes carried over from the parent DFIRM data through the selection process. The attribute data could also be edited during an edit session by the testers.

The testing of the toolset was successful and the logic of the tool layout seemed to help the testers understand the steps involved. The Editor Toolbar did cause some confusion about setting which feature class to edit, but the testers were able to figure out why this step was necessary after some assistance and further explanation. Having few editor buttons on the Flood Hazard Scenario Creator toolbar did help the testers with saving edits and stopping the edit session, so the implemented toolbars were not changed based on this testing.

\subsection{Testing the Models}

The testers also used their newly created scenario feature classes to perform some analyses using the models implemented for the application. The testers found the guidance text in the model dialog boxes to be helpful in understanding what the model parameter fields were expecting as far as inputs in those fields. The implementation of the results being in tables which are added to the ArcMap Table of Contents under the Source tab seemed clumsy and hard to grasp for the testers. After using several of the models, the testers became more familiar with the process and were able to find and open the result tables more easily. Some of the guidance text in the dialogs was changed based on comments from the testers that the previously implemented text was not clear.

The testers worked through all five models and were also asked to use the Select by Attributes to determine the PAL Levees for San Joaquin County, since none were in the table for Sacramento County. The testers were able to do this task easily once they understood how the Select by Attribute dialog box worked. The testers were also able to find all the mapping projects for Sacramento County using the Select by Attribute function in the options portion of the table dialog box.

The results of the models were compared to what the values were likely to be and found to be accurate. The only changes to the models were to the text in the model dialog boxes to make it clear to the user what was expected in the input fields. The resulting 
data generated by the models would still need to be mapped to prove that the new feature classes created were complete.

\subsection{Mapping the Results}

The implementation of the application provided the end user with the ability to generate results to show which areas are impacted. The models provide the user with a new feature class that can show the areas being impacted so that the numerical results can be backed up and further communicated visually. The application was used during testing to ensure that the results of the models could be mapped using the attributes added by the models. Both the Population Impacted and Housing Units Impacted models were used to produce maps showing the results of the models. This process is described below for each model along with the map product generated.

The Population Impacted model creates a feature class from the clipped Census_Blkgrp feature class which can be symbolized in ArcMap to show where the people are and the distribution of the populations in terms of the clipped block groups. The symbology is based on the Pop_Impacted attribute, a new field added by the model to keep track of the population included in the clipped block group. Symbolizing the quantities through graduated colors easily shows where the higher populations and lower populations impacted by the flood hazard scenarios are located. Figure 5.1 shows a map of the distribution of population for the clipped census block groups using the imagery available from ESRI's web mapping service as a background. Making the block group symbology transparent allows the user to see through the block groups to see the imagery underneath and provide more information as to the make-up of the areas that are impacted. This provides a very powerful communication component to the results being generated with this application. 


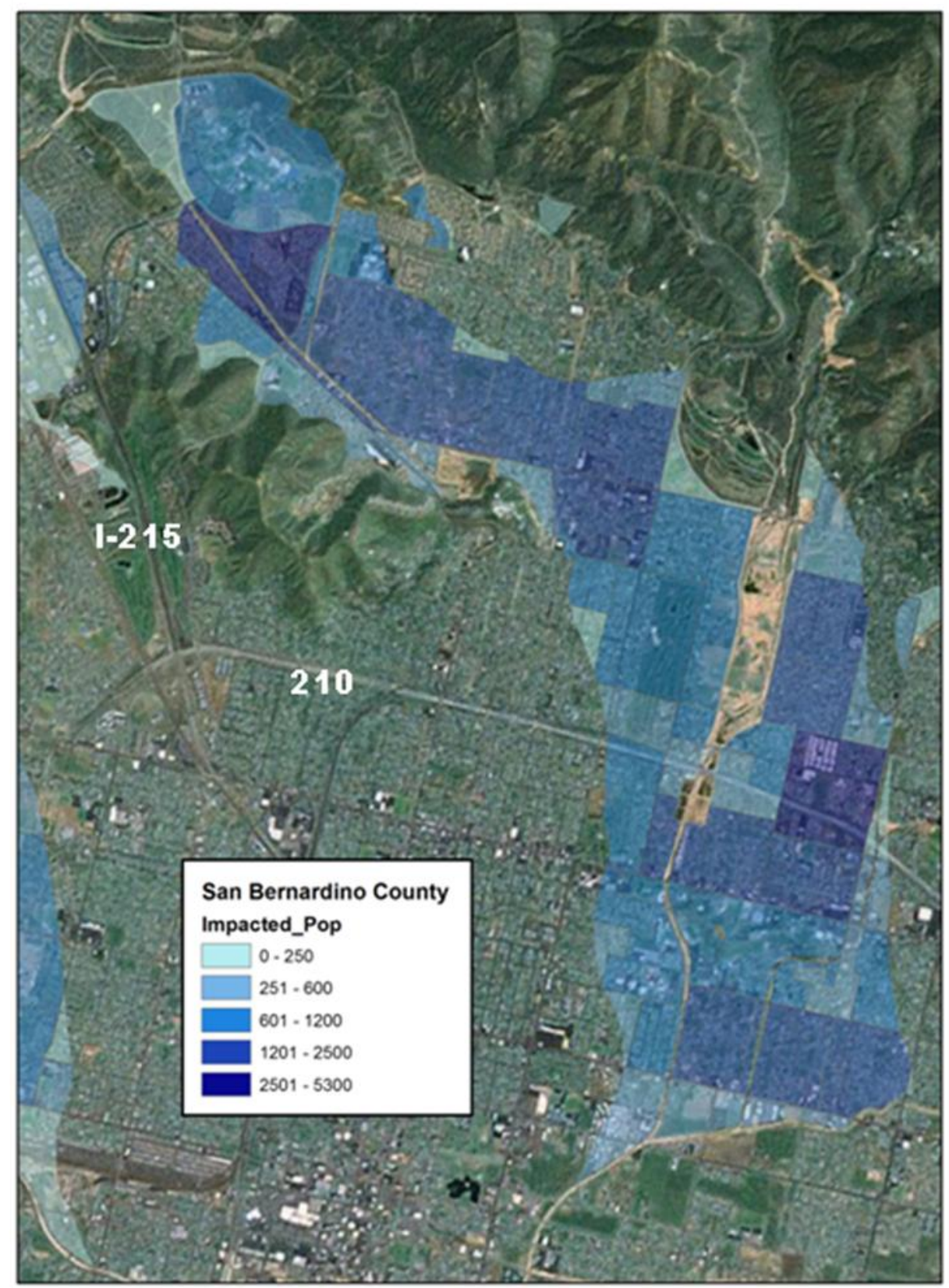

Figure 5.1 Results of the Population Impacted Model in an Area of San Bernardino

The results of the Housing Units Impacted model can also be mapped to better understand the extent of the hazard. A dot density was used to show the distribution of the housing units in the census block polygons. The Levee Protected Areas are shown to show the extent of the flooding if the levees are not considered as providing protection. The levees are also shown to reference their locations to the flood hazards and the housing units. Figure 5.2 provides a clear picture of where the housing units are located and the number that are located in general areas. The application provides the end user with the flexibility to show information that helps communicate to decision makers and stakeholders the impacts of different flood hazard scenarios such as the one shown below. 


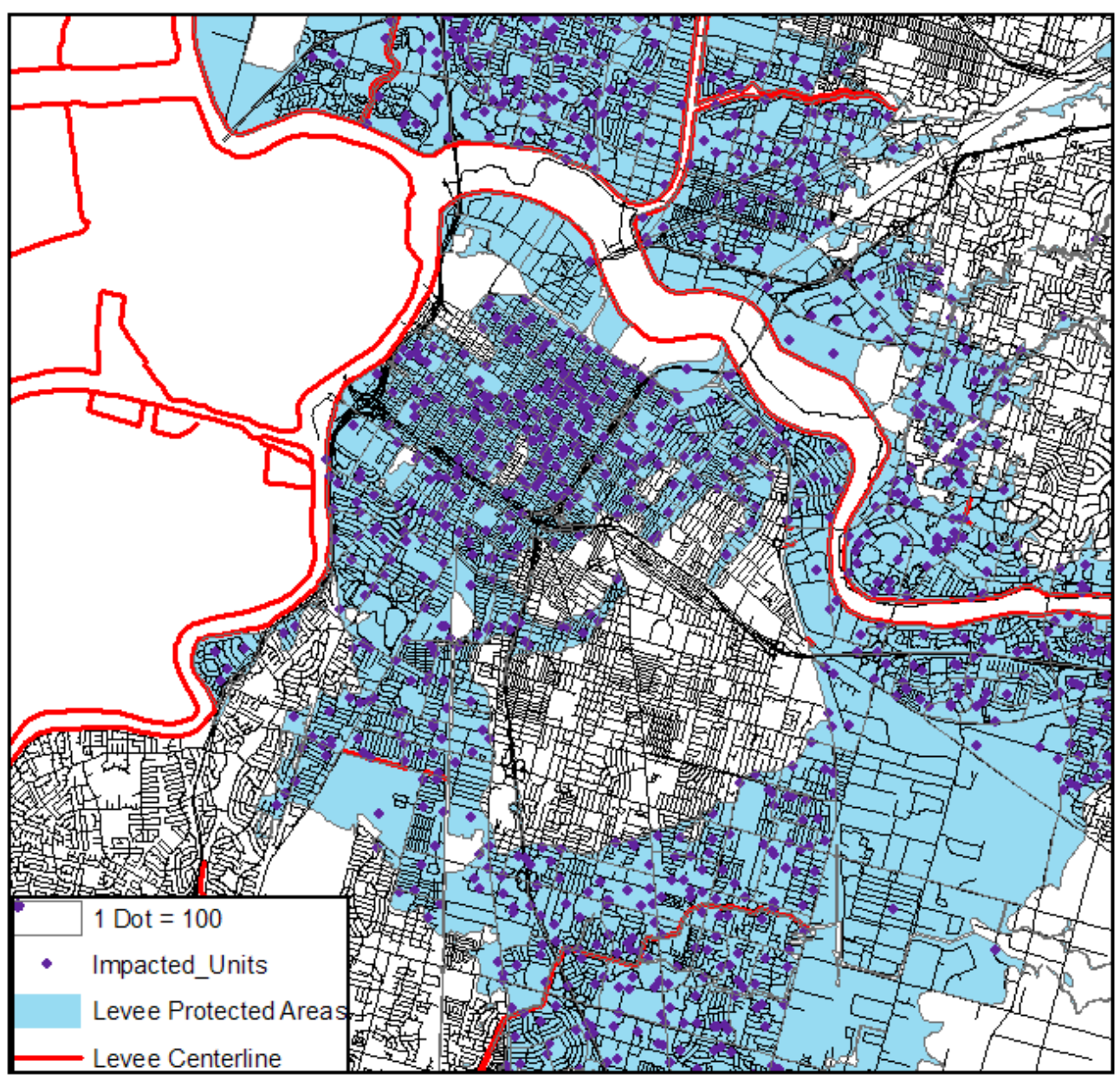

Figure 5.2 Results of the Housing Units Impacted Model for an Area in Sacramento

Producing maps of the model results proved that the application functions properly and the resulting feature classes have the data necessary to produce meaningful maps. This concluded the testing of the application. 


\section{Conclusions}

The final conclusions for this application are broken down between the process to develop and build the application, the application itself, and future work. The success of the entire application can be attributed to the process and the successful implementation of the geodatabase, toolset, and the models that make up the application in ArcGIS.

\subsection{Process}

The process used to develop and build this application was successful in producing a final application based on ArcGIS Version 9.2. The process was iterative and the individual components of the application were implemented in parallel rather than through a waterfall type process as originally planned. This allowed for changes to be made throughout the development and implementation phases. This greatly enhanced the final product by allowing flexibility in the design and implementation that would not have been present if the implementation had occurred in stair-stepped stages as originally proposed. The parallel processing may have caused delays and additional time to be taken during the implementation of the application's components but the benefits to the final application outweigh the cost of the additional time.

Most of the problems were found early and corrected so that only minor changes were necessary as a result of the testing of the application. The additional time spent developing the application may have offset the time that would have been spent making corrections and changes to the application after testing.

\subsection{Application Results}

The application performed well overall. The components worked together logically and were built to complement one another. The results of the application meet the requirements set out for the system and provide the analytical capability required by the client. Managing the geodatabase through ArcCatalog using its existing tools in Version 9.2 and the integration of the toolsets and models using an MXD through ArcMap made the system user friendly, while at the same time achieving the goal of assisting end users to become more familiar and proficient at using ArcGIS in their daily work.

The geodatabase implementation allows the user to update and add data as needed. The tools and models work extremely well based on the geodatabase as the foundation of the application. The implemented geodatabase is logical and easy to understand even though there are multiple data sets in the application.

The toolset implemented is simple and follows the natural workflow for defining flood hazards for the scenarios the user wishes to define. The toolbars are laid out so as to not overcomplicate the process and to serve as a guide to the end user. The effort is also 
minimized for the end user through the use of the tools, especially where flood hazard data is available from FEMA's DFIRMs. The toolset creates the feature classes for the scenarios to be stored in the geodatabase and used in the models for analyses. Both the other components work well with the toolset component.

The models implemented in this application use the data in the geodatabase, as well as the new spatial data created using the toolset to perform geoprocessing analyses that calculate the required variables for the end users. The models successfully calculate the population and housing unites impacted by a specific flood hazard scenario, total population, and housing units of an area, and the length of levee that is present for an area. The results of the models can be shown through both numerical and graphical means using ArcMap. The application provides the client with the tools to perform the analyses to calculate the results required of the application.

The overall implementation of the application provides a well-designed process for the end user to maintain the data in the geodatabase and perform updates to the data. It allows the user to create flood hazard scenarios based on the available data to be used for analysis. The models automate the analysis to calculate the required numerical results and feature classes for graphical representations. The implementation is a success but can also be enhanced as the end users define other analyses they would like to perform using the application.

This application provides a demonstration of the power the new flood hazard data produced by FEMA brings to their work. It shows how coupling the flood hazard data with other spatial data makes performing analyses and producing results in a short time period possible with proper design and implementation. The greatest success of this application will be that it is the model for other such applications used by FEMA as part of its modernization efforts.

\subsection{Future Work}

During the implementation of this application, future work items were identified that may enhance the functionality for the client. These proposed future enhancements begin with working towards fulfilling the Optional Requirements that were identified for the application. The other enhancements were not included as part of the original requirements, but are presented for consideration.

The application was implemented using an Albers Equal Area Conic projection for the continental United States. An enhancement to this application and possibly for ArcGIS would be to create a system that would automatically select the best projection based on user-defined preferences for projecting data. This would make the application easier for non-GIS professionals and broaden the applicability of the application to other areas without reprojecting for each area the user is interested in analyzing.

The application was implemented using the Census Block Group data, but the Block data could be used to better approximate the population and housing units in those areas. The 
Block data is at a finer scale than the block group polygons which are comprised of the smaller block polygons. The block data has the population information but not the other census information which is used for this application. The same area ratio approach could be used to account for the areas that are impacted by the flood hazard scenario, but the finer scale would allow for a more accurate approximation of the population impacted.

This application was implemented to analyze flood hazard scenarios based on the userdefined extents, but there would be value in showing uncertainty in cases where the flood hazards may not be as clearly defined. This could be valuable in communicating the uncertainty of the data and the results to decision makers. A veniet could be used to show the degrees of uncertainty or fuzziness of the data and results. This would be clearly represented visually and allow a different take on the results of the analyses to be communicated. This type of uncertainty mapping could also be used to show levee failure risk areas which are currently not part of the FEMA flood hazard data.

Further enhancements could be made to perform additional analyses if additional data, such as more demographic data, were added to the system to provide other statistics to the user such as property values impacted or businesses impacted. FEMA also has insurance policy and claim information available that would provide for analyses to determine the policies present in an area. These enhancements would showcase the value of flood hazard data and broaden the stakeholder audience that can benefit from the results of such analyses.

Adding a spatial component to the PAL_Tracking and Study_Tracking could also provide more analytical power through the use of an application such as this in the future. If the Study_Tracking data included the specific areas where certain tasks were located, a more thorough evaluation could be made of the impacts on the study and the resulting flood hazard mapping. This would be useful in terms of future planning, assessments, and monitoring.

ArcServer could also be evaluated to see what additional benefits would be gained through making this application available via the internet. This could allow more users to access the application and the data stored in the geodatabase. As FEMA completes the National Flood Hazard Layer containing all the DFIRMs developed for the country, this would become a very powerful tool to FEMA and its user community. 



\section{References}

Ahmad, S., \& Simonovic, S. P. (2004). Spatial System Dynamics: New Approach for Simulation of Water Resource Systems. Journal of Computing in Civil Engineering, October 2004, 331-340.

Jankowski, P., Robischon, S., Tuthill, D., Nyerges, T., \& Ramsey, K. (2006). Design Considerations and Evaluation of a Collaborative, Spatio-Temporal Decision Support System. Transactions in GIS, 10(3), 335-354.

Jelinski, D. E., \& Wu, J. (1996). The modifiable area unit problem and implications for landscape ecology. Landscape Ecology, 11(3), 129-140.

Levy, J. K. (2005). Multiple criteria decision making and decision support systems for flood risk management. Stochastic Environmental Research and Risk Assessment, $19,438-447$.

Mennis, J. (2002). Using Geographic Information Systems to Create and Analyze Statistical Surfaces of Population and Risk for Environmental Justice Analysis. Social Science Quarterly, 83(1), 281-297.

Sebhat, M., \& Heinzer, T. (1997). The Development of an ArcInfo Interface to the National Weather Service DAMBRK Model. Paper presented at the ESRI International User Conference. Retrieved 1/31/08, from http://gis.esri.com/library/userconf/proc97/proc97/abstract/a581.htm

Steel, D. G., \& Holt, D. (2008). Analysing and Adjusting Aggregation Effects: The Ecological Fallacy Revisited. International Statistical Review/Revue Internationale de Statistique.

Vickers, B. (1994). Designing Layered Funcationality Within Group Decision Support Systems. Decision Support Systems, 11, 83-99.

Witherell, B. B., \& Hahn, M. (2000). Environmental Risk Management and Communication: A Case Study Using GIS Tools. Paper presented at the ESRI International User Conference.

Zerger, A. (2002). Examining GIS decision utility for natural hazard risk modelling. Environmental Modelling \& Software, 17, 287-294. 

